\title{
Hydrological discharges and motion of Fels and Black Rapids Glaciers, Alaska, U.S.A.: implications for the structure of their drainage systems
}

\author{
C. F. Raymond, R.J. Benedict, \\ Geophysics Program, University of Washington, Seattle, Washington 98195, U.S.A. \\ W. D. Harrison, K. A. Echelmeyer, \\ Geophysical Institute, University of Alaska-Fairbanks, Fairbanks, Alaska 99701, U.S.A. \\ M. STURM \\ U.S. Army Cold Regions Research and Engineering Laboratory, Fairbanks, Alaska 99701, U.S.A.
}

\begin{abstract}
Characteristics of the hydrology and motion of Black Rapids and Fels Glaciers, Alaska, were observed from 1986 to 1989. Hydrological measurements included stage, electrical conductivity and suspended-sediment concentration in the discharge stream of each glacier, and were made at $0.5-1 \mathrm{~h}$ intervals continuously through most of the melt seasons. Variations in the glacier speed were monitored through the full year at a number of locations along the length of each glacier using time-lapse photography (1 d time resolution), strain meters $(0.5-1 \mathrm{~h}$ resolution) and seismometers set up to count acoustic emissions. Both glaciers show similar seasonal, diurnal and short-term event changes in hydrological discharges and ice speed. The hydrological behavior is analyzed in terms of a "fast" sub-system composed of surface streams, moulins and large tunnels with discharge that responds rapidly and a "slow" sub-system composed of heterogeneous small passageways through the ice and distributed over the bed that maintain approximately uniform discharge over a day. The timing and amplitude of water discharge in the diurnal cycle indicate that roughly $10-40 \%$ of the water is routed directly into the fast system. The remaining $90-60 \%$ of the water enters the slow system. Dilution of the solute discharged from the slow system by the variable discharge in the fast system results in changes in water discharge and solute concentration that are approximately equal in relative amplitude and inversely related. A small time lag from discharge maximum (minimum) to solute minimum (maximum) suggests that the fast system is confined to roughly the lowermost $30-40 \%$ of the full glacier length. The residence time of water in the fast system is short compared to $1 \mathrm{~d}$. The slow system contains both short- and long-residence time passages. Characteristics of the diurnal cycles are somewhat variable through the melt season, but no systematic evolutionary patterns were discerned even though large changes in the mean discharges of water and solutes occur, which suggests parallel evolution of the variables that control the response of the fast system. Events were characterized by contemporaneous increases in suspended-sediment concentration in the discharge water and distinct changes in straining on the glaciers. Events caused by increases in melt or precipitation related to weather and events related to release from reservoirs internal to the glaciers could be distinguished based on the changes in electrical conductivity of the discharge water. The correlated changes in sediment discharge and motion of the glaciers indicate that the events were associated with temporary modifications of the slow passages distributed over the bed that allowed enhanced sliding and access of basal water flow to erosion products. Hydrological differences between Black Rapids and Fels Glaciers can be explained by differences in the size of the glaciers. If there is a difference in bed structure that explains the difference in dynamics (surge - Black Rapids Glacier - versus non-surge - Fels Glacier), it does not affect the hydrological parameters that were observed.
\end{abstract}

\section{INTRODUGTION}

The possible coupling between the hydrology and motion of a glacier has long been recognized. Observations have now clearly tied various kinds of glacier-velocity changes to changes in the input, output or storage of water in the glacier system. Examples are: glacier surges (Kamb and others, 1985; unpublished information from A. Post), seasonal variations (Hodge, 1974; Iken and others, 1983; Hooke and others, 1989) and short-term changes sometimes 
referred to as "mini-surges" or "motion events" (Iken and others, 1983; Harrison and others, 1986; Humphrey and others, 1986; Iken and Bindschadler, 1986; Kamb and Engelhardt, 1987; Hooke and others, 1989).

In this paper, we compare Black Rapids and Fels Glaciers in the central Alaska Range (Fig. 1) using highresolution time series of a number of hydrological and icedynamical parameters that extend through much or all of the year for several years. On each glacier, it is possible to examine the relationships between these parameters on a variety of time-scales spanning short events of hours or less, diurnal variations, seasonal patterns and year-toyear changes. The relative timing of dynamic events on the glaciers and discharges of water, solutes and sediments are of particular interest for examining the structure of the drainage system and its relation to the ice flow.

Black Rapids Glacier is a large surge-type glacier that last surged in 1937 (Hance, 1937) and could surge again in the near future (Post, 1969). Fels Glacier is a smaller glacier that is not known to surge. Geometrical information about these glaciers is given in Table 1.

Table 1. Glacier characteristics and relation to stream sites

\begin{tabular}{|c|c|c|c|}
\hline & & $\begin{array}{c}\text { Black Rapids } \\
\text { Glacier }\end{array}$ & $\begin{array}{l}\text { Fels } \\
\text { Glacier }\end{array}$ \\
\hline $\begin{array}{l}\text { Glacier type } \\
\text { (last surge) }\end{array}$ & & $\begin{array}{l}\text { "Surge-type" } \\
(1936-37)\end{array}$ & Normal \\
\hline Glacier length & $(\mathrm{km})$ & 41 & 12 \\
\hline Glacier width & $(\mathrm{km})$ & $2-3$ & 1 \\
\hline $\begin{array}{l}\text { Glacier area } \\
\text { including tributaries }\end{array}$ & $\left(\mathrm{km}^{2}\right)$ & 150 & 18 \\
\hline Cientral ice thickness & $(\mathrm{m})$ & 500 & 250 \\
\hline Average surface slope & & 0.025 & 0.07 \\
\hline $\begin{array}{l}\text { Typical central flow-line } \\
\text { speeds }\end{array}$ & $\left(\mathrm{ma}^{\prime}\right)$ & 100 & $70-100$ \\
\hline Elevation range & (m) & $2580-990$ & $2500-980$ \\
\hline Drainage basin area & $\left(\mathrm{km}^{2}\right)$ & 400 & 50 \\
\hline $\begin{array}{l}\text { Distance from terminus to } \\
\text { stream observation site }\end{array}$ & $(\mathrm{km})$ & 1 & 0.1 \\
\hline Stream-site gradient & & $0.01-0.02$ & 0.05 \\
\hline
\end{tabular}

Mid-summer hydrological characteristics of the streams draining the glaciers are summarized in Table 2. Both glaciers lie in the vicinity of the Denali Fault and the central part of Black Rapids Glacier flows along the main fault. Both glaciers descend over a similar altitude range (Table 1). Winter snowfall deposits about $3-4 \mathrm{~m}$ of snow on the upper reaches of the glaciers. Exposure of the terminus areas of the glaciers to wind often results in much thinner snow accumulations on the lower parts of the glaciers. Summer melting occurs over the full length of the glaciers. Black Rapids Glacier is known to be essentially temperate (Harrison and others, 1975) and this is probably the case for Fels Glacier.

Table 2. Stream characteristics typical of July

\begin{tabular}{lccc}
\hline & & $\begin{array}{c}\text { Black Rapids } \\
\text { Glacier }\end{array}$ & $\begin{array}{c}\text { Fels } \\
\text { Glacier }\end{array}$ \\
\hline Water depth & $(\mathrm{m})$ & 1.5 & 0.8 \\
Cross-sectional area & $\left(\mathrm{m}^{2}\right)$ & $\sim 28$ & $1.7-4.5$ \\
Surface velocity & $\left(\mathrm{m} \mathrm{s}^{1}\right)$ & 5 & $1.7-2.8$ \\
Discharge & $\left.\left(\mathrm{m}^{3}\right)^{1}\right)$ & $\sim 100$ & $3-13$ \\
Suspended sediment & $\left(\mathrm{gl}^{1}\right)$ & 3 & 5 \\
Suspended-sediment flux & $\left(\mathrm{kg} \mathrm{s}^{1}\right)$ & 300 & 1565 \\
lonic impurity concentration & $\left(\mathrm{mgl}^{1}\right)$ & 4.5 & 7.7 \\
lonic impurity flux & $\left(\mathrm{kgs}^{1}\right)$ & 4.5 & $0.2-1.0$ \\
& & & \\
\hline
\end{tabular}

The comparison of these nearby glaciers provides a means to examine whether surge-type glaciers have distinguishing characteristics during the normal phase of flow, as might be possible if the surge behavior arises from special bed characteristics. The geometrical characteristics of Fels Glacier are very similar to those of surge-type Variegated Glacier (Bindschadler and others, 1977), which provides another comparison that could isolate special characteristics associated with surge behavior.

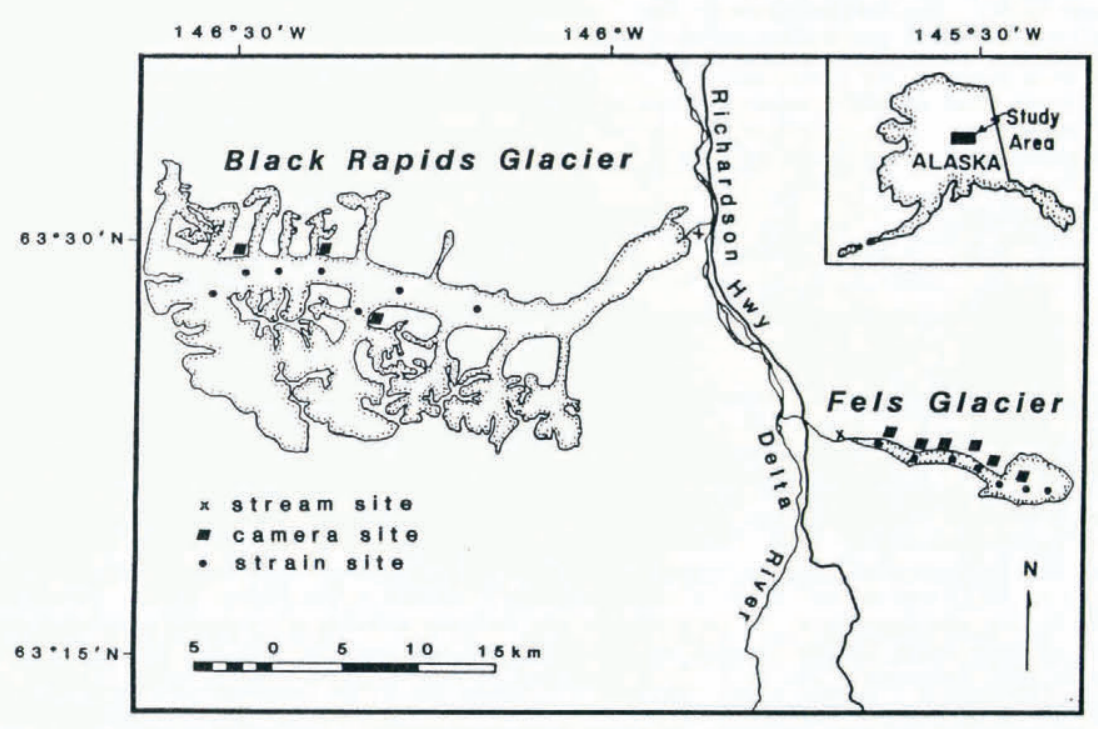

Fig. 1. Map of Black Rapids and Fels Glaciers showing measurement sites. 


\section{MEASUREMENTS}

\section{A. Methods}

The hydrological outputs from the glaciers were monitored through most of the melt seasons with automated instruments sampling every $0.5-1 \mathrm{~h}$. These instruments measured water-surface height (stage) using ultrasonic distance ranging, electrical conductivity (EC) using a resistance cell, turbidity (TR) using light transmission and water temperature with a thermistor. Instrument deployment was similar to methods used by Humphrey and others (1986). The location and configuration of the instruments were chosen to achieve reliability in the glacier-fed stream environment of unstable banks, high water velocity, entrained icebergs and high sediment transport. Table 1 describes the locations of streamsampling sites in relation to the glacier termini. Alongstream traverses of EC and suspended-sediment concentration showed that, during summer conditions, the stream sites were representative of the termini. Several times during each melt season, stage, water depth, surfacewater velocity and EC were measured manually, and water samples were taken to check calibrations and provide accessory information.

Water discharge was not measured for either of the glacier streams. Rough estimates are possible at times when water velocity was measured, which leads to the numbers in Table 2. Fluctuations in stage give a qualitative indication of trends in discharge. Because of cut-and-fill in the channel and lack of cross-sectional measurements, we cannot fully quantify the water discharge. For relatively small, short-term changes, such as during the diurnal cycle, we used Manning's equation assuming constant roughness and channel shape to calculate the fractional changes in discharge from the fractional changes in water depth. Determination of the total discharge from Black Rapids Glacier is further complicated by two small tributaries that enter the stream below the instruments.

Changes in EC are caused by changes in solute chemistry of the water. Water temperature always remained within $1 \mathrm{~K}$ of freezing and had negligible effect on $\mathrm{EC}$ variations. The details of the chemistry have not been investigated. If the proportions of ionic components did not change with time, which in some cases is approximately true in glacier-fed streams (e.g. Raiswell and Thomas, 1984; Thomas and Raiswell, 1984), then EC would be proportional to the total solute concentration. Standard conversion for ground water (measured at $0^{\circ} \mathrm{C}$ ) indicates that solute concentration in $\mathrm{mgl}^{-1}$ and $\mathrm{EC}$ in $\mathrm{mS} \mathrm{cm}^{-1}$ are roughly equal Greenberg and others, $1981)$.

The relationship between TR and suspended-sediment concentration was investigated using water samples collected from the same depth as the turbidity sensor $(\approx 0.1 \mathrm{~m}$ beneath the surface). We present TR converted to approximate sediment concentration based on calibration curves derived from regression of these data (Raymond and Benedict, 1989). TR and sediment concentration were only roughly correlated with substantial scatter $(\approx 50 \%)$. The usual calibration between $\mathrm{TR}$ and sediment concentration appeared to break down during some intervals of high turbidity when the turbidity rose substantially more than expected from the sediment concentration because of a fining of the grain-size distribution. Therefore, the calibrated turbidity gives only a rough estimate of the level of suspended-sediment concentration. Occasional measurements of suspendedsediment concentration versus depth showed that the surface samples were representative of the water column except for an increase in the coarse fraction near the bed.

Measurements of inputs to the glacier hydraulic system were limited. Air temperature, recorded halfhourly, and half-day, integrated precipitation measured at stream sites provide indicators of glacier ablation rate and rainfall input. Discharge and EC in supraglacial streams and in streams coming from the valley walls were measured once on each of the glaciers.

The motion of the glaciers was monitored using periodic surveys of markers to obtain seasonal to annual velocity averages. Resolution of velocity changes on a $1 \mathrm{~d}$ time-scale was achieved using time-lapse photography of markers on the glacier surface with cameras fixed on the margins. (For a description of methods see Harrison and others (1992).) Motion changes at shorter time-scales were examined using strain meters and seismometers that were recorded every $0.5 \mathrm{~h}$ with data loggers. Strain meters measured on a $1 \mathrm{~m}$ base line and were installed vertically at depths of $7-15 \mathrm{~m}$ in steam-drilled holes which refroze after installation. Strain rate averaged over $4 \mathrm{~h}$ was calculated at a given time from strain sampled $2 \mathrm{~h}$ before and after that time. We are concerned only with the timing of strain-rate changes and do not here attempt to calibrate the strain readings. The seismic recording used $10 \mathrm{~Hz}$ geophones connected directly to a data logger. The voltage input was processed by the data logger and converted to counts representing the level of seismic activity. Similar to strain rate, the units of seismicity can be interpreted only in a relative sense. Harrison and others (1993) gave more details on the strain meters and seismic monitoring methods.

\section{B. Results}

Figure 2 shows the hydrological time series for Black Rapids Glacier during the 1989 melt season and for Fels Glacier during the 1987 melt season. To describe dynamic activity of each glacier for comparison with hydrological discharges, strain rate and seismicity are shown in Figure 2 for one location on each glacier. These are the most complete and reliable seasonal time series from each glacier. The following analysis will focus on these two data sets but we will also refer to observations from other years. Figure 3 shows the intervals in 1986-89 for which there are reliable measurements. All hydrological time series and associated measurements are available from World Data Center A-Glaciology (Raymond and Benedict, 1989). Extensive measurements of velocity, strain rate and seismicity are also available from the World Data Center in another report (Harrison, 1990).

Processing steps applied to the hydrological time series are illustrated in Figure 4. Examples are shown for relatively noisy data as was typical of the stage measurement (Fig. 4a) and smooth data as was typical of the EC measurement (Fig. 4b). The data were first smoothed 
BLACK RAPIDS GLACIER, 1989
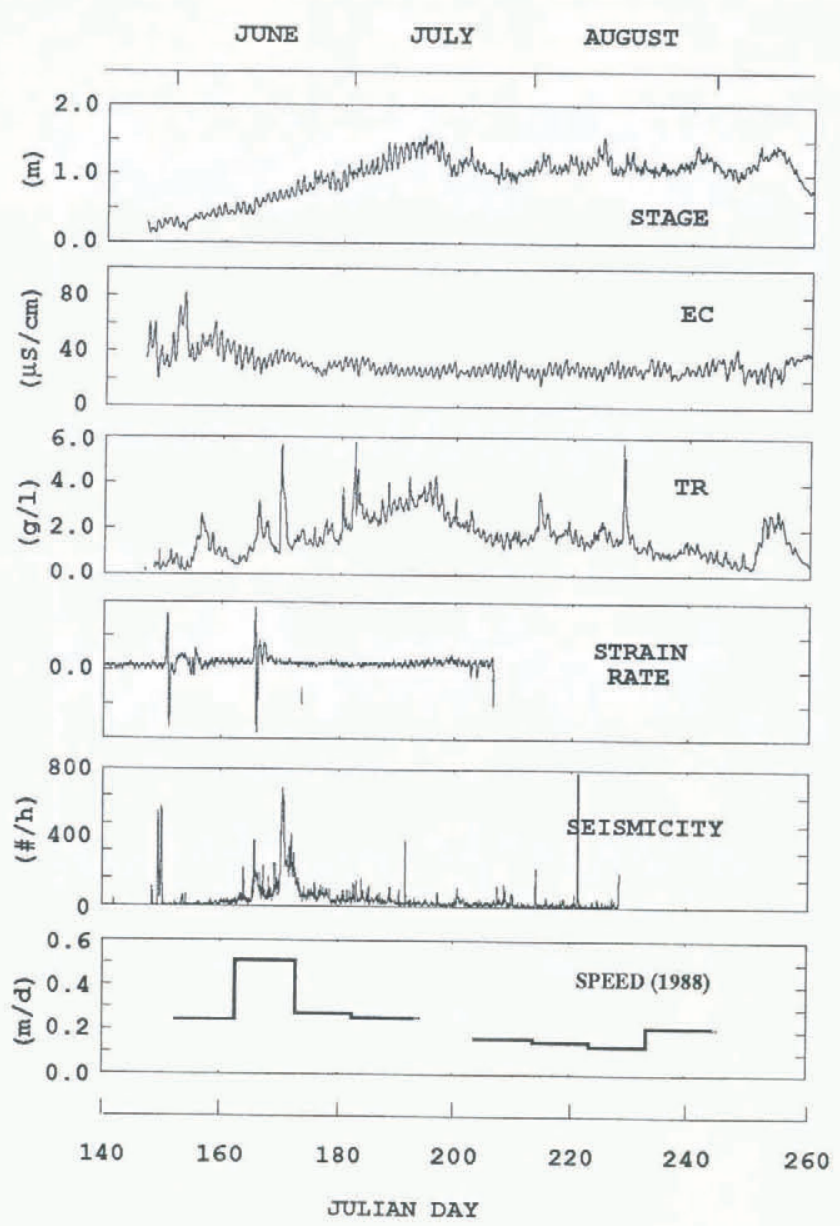

Fig. 2. a. Time series of hydrological and ice dynamics data for Black Rapids Glacier in 1989. Strain rate represents extension along the vertical direclion. Speed data for 1989 are not available. Speed averaged over approximately 2 weeks is shown for 1988 to illustrate the paltern of variation through the mell season.

and interpolated to fill in short gaps using optimal interpolation (visible as thin curves in Figure 4 except where obscured by data points). The curves in Figure 2 show the smoothed data. The smoothed data were then low-pass filtered using a $24 \mathrm{~h}$ running mean. The resulting curve shows the secular trends happening over multi-day intervals (heavy solid curve in Figure 4). This trend curve was subtracted from the smoothed data to reveal detrended variations at time-scales of about a day or less (dashed curve in Figure 4).

\section{GHARACTERISTICS OF TIME VARIATIONS}

\section{A. Seasonal evolution}

The seasonal pattern of hydrological discharges is illustrated by the data from Black Rapids Glacier during 1989 (Fig. 2a). Before Julian day 147, the river surface at the measurement site was obscured by ice and drifted snow. The first useful measurements start on that date. The record showed a gradual rise in stage for roughly $40 \mathrm{~d}$ until about Julian day 190. After that, the stage showed no strong long-term trend and remained at high levels or
FELS GLACIER, 1987
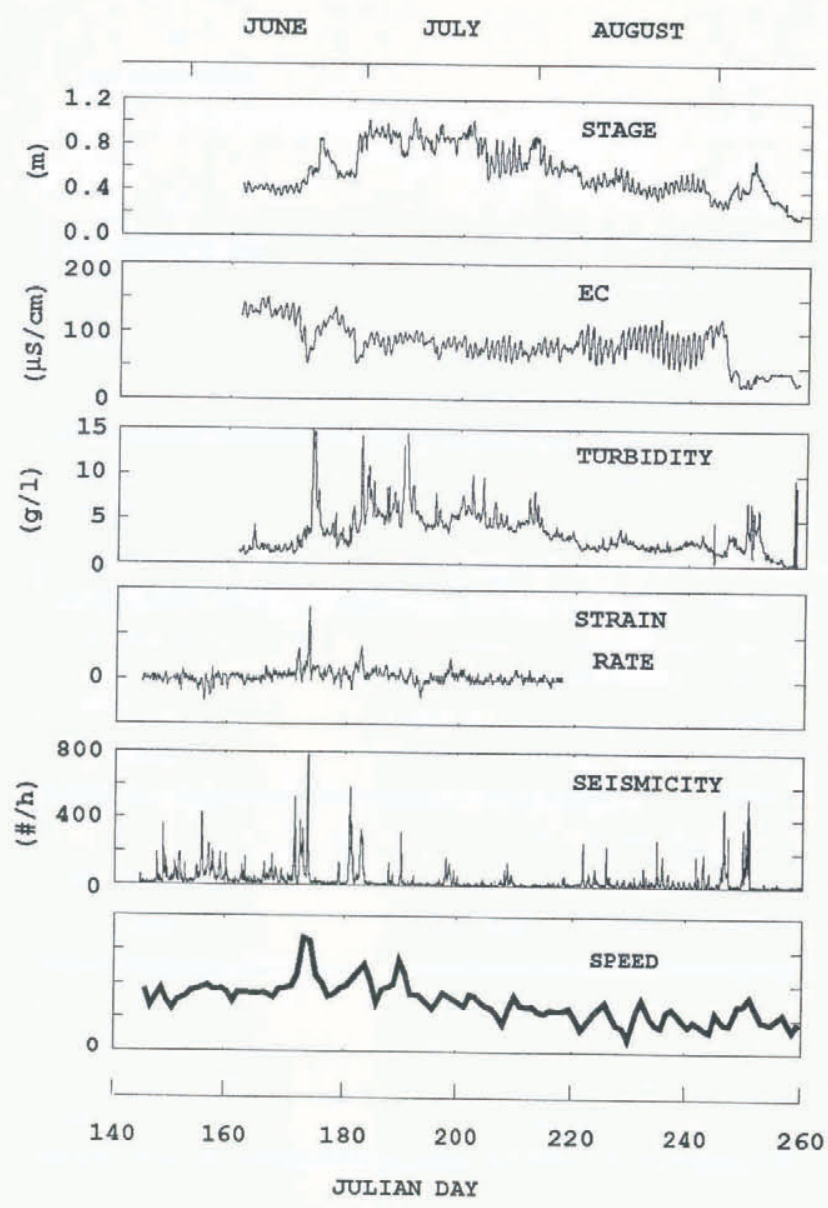

Fig. 2. b. Time series of hydrological and ice-dynamics dala for Fels Glacier in 1987. Strain rale represents extension along the vertical direction. Speed is based on film-plane displacement on a fixed lime-lapse camera withoul scaling from photogrammetric corrections.

decreased only slightly for approximately $60 \mathrm{~d}$ until about Julian day 250. Subsequently, there was a relatively rapid decrease in stage. EC showed opposite trends compared to stage. EC times water discharge is approximately proportional to solute flux. During the melt season, the water discharge increased much more than the solute concentration decreased, so the solute flux increased. Turbidity increased during the initial period of rising stage days $150-190$ but during the following period of relatively constant stage (days $220-250$ ) TR decreased. The suspended-sediment discharge therefore increased rapidly and declined gradually over these time intervals.

The discharges from Fels Glacier in 1987 (Fig. 2b) followed similar patterns. Some differences in comparison to Black Rapids Glacier in 1989 were: (i) a more noticeable trend of declining stage through the mid-summer, (ii) no observed abrupt decrease in stage in the late summer, (iii) more prominent multi-day and diurnal variations.

Although the data from other years are less complete, they show the same general patterns with some differences probably reflecting year-to-year differences in the weather (Raymond and Benedict, 1989).

The broad seasonal patterns of ice velocity are similar on both glaciers (Fig. 2). A broad minimum in velocity 

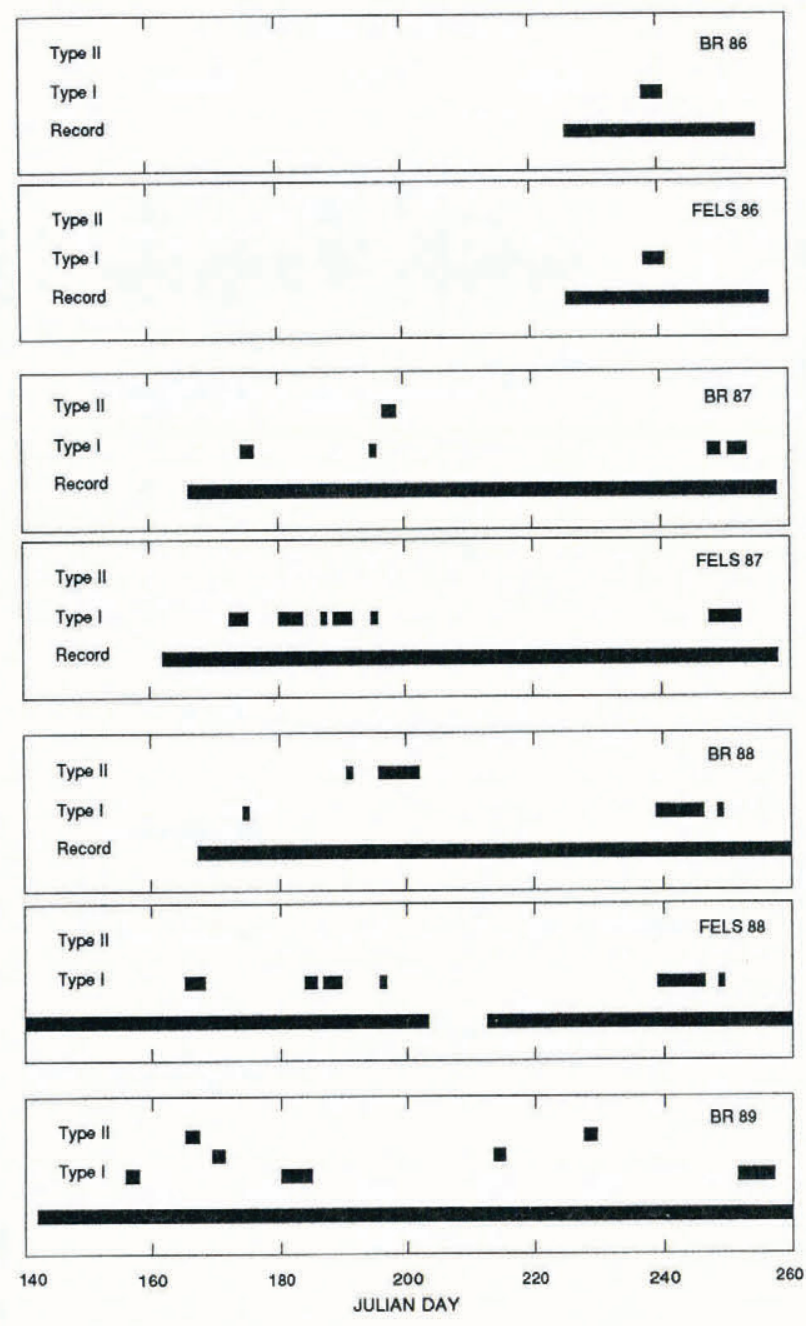

Fig. 3. Intervals of successful automated observations for stream stage, electrical conductivity (EC) and turbidity on Black Rapids and Fels Glaciers in 1986, 1987, 1988 and 1989. Also shown are the occurrence of type I, type II and intermediate-type events.

occurs at a time that depends on location but is typically in late summer. The highest speed is in late June and early July. Above the equilibrium lines, the data are sparse but the available information indicates that the seasonal variations are small in comparison to lower elevations.

\section{B. Diurnal variations}

Diurnal variations of hydrological variables have been examined for Fels and Black Rapids Glaciers using the smoothed and detrended time series described in section $2 \mathrm{~B}$. The data for stage and EC were stacked to identify the characteristic phase and amplitude relationships of the diurnal cycle. The stacking was done in $20 \mathrm{~d}$ blocks through the summer to test for systematic evolution in the pattern of diurnal variation (Fig. 5). On both glaciers, the diurnal variations of stage and EC were approximately sinusoidal and inversely related. The diurnal variation of TR investigated by the same analysis was more complex because the stacking was affected by spikes from turbidity events that may or may not have been related to the diurnal cycle.
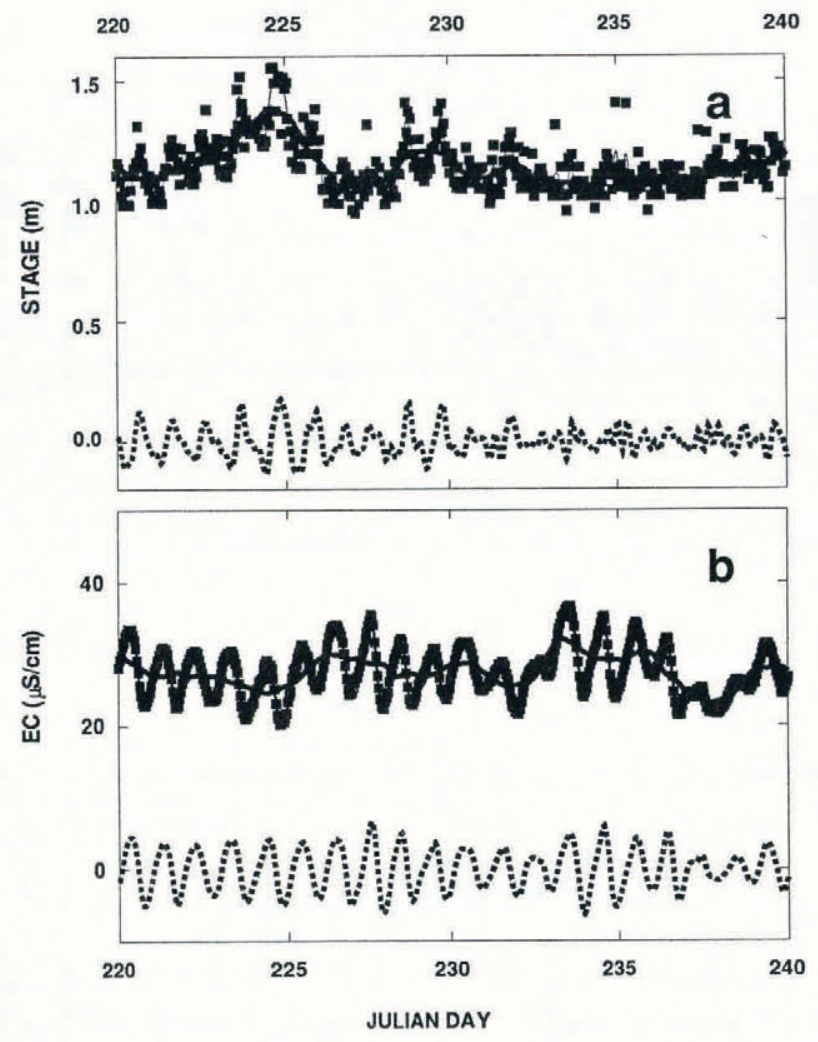

Fig. 4. Example of processing of hydrological data showing data points, smoothed matching curve (thin curve following points), low-pass filtered trend curve (thick curve) and curve of detrended short-term variations (dashed curve). Measurements are from Black Rapids Glacier on Julian days 220-240 (8-28 August) 1989.

(a) Stage, (b) Electrical conductivity (EC).

A measure of the amplitude of the diurnal cycle is described in Figure 5 in terms of the half-amplitude of variation (full amplitude being the minimum-to-maximum change) divided by the mean and is called relative amplitude. The relative amplitude rose in the early melt season and declined in the late melt season. On Black Rapids Glacier, in 1989 (Fig. 5a), the relative amplitude was high immediately after the stream surface was exposed, indicating a very rapid rise in the relative amplitude early in the melt season and a gradual decline thereafter. However, this was not necessarily the case in other years, for example in 1987, when the highest relative amplitude occurred late in the melt season around day 230. The rise and fall of relative amplitude was gradual on Fels Glacier in 1987 (Fig. 5b) and also in 1988.

The variations in stage $h$ (Fig. 5) can be related to water discharge $Q$ using Manning's equation. For small deviations $\hat{Q}$ and $\hat{h}$ from means $\bar{Q}$ and $\bar{h}$, it predicts $\hat{Q} / \bar{Q}=k \hat{h} / \bar{h}$ with $k \approx \frac{5}{3}$ for the vertically walled Fels Glacier stream and with $k>\frac{5}{3}$ for Black Rapids Glacier stream, which has sloped banks. Assuming that concentration of solutes $C$ is linearly related to $\mathrm{EC}$, relative amplitude of $C$ is the same as for EC (Fig. 5). The solute flux is $Q C$. Small fractional changes in $Q C$ are given approximately by $\hat{Q} / \bar{Q}+\hat{C} / \bar{C}$. Since the fractional 
(a) BLACK RAPIDS GLACIER, 1989
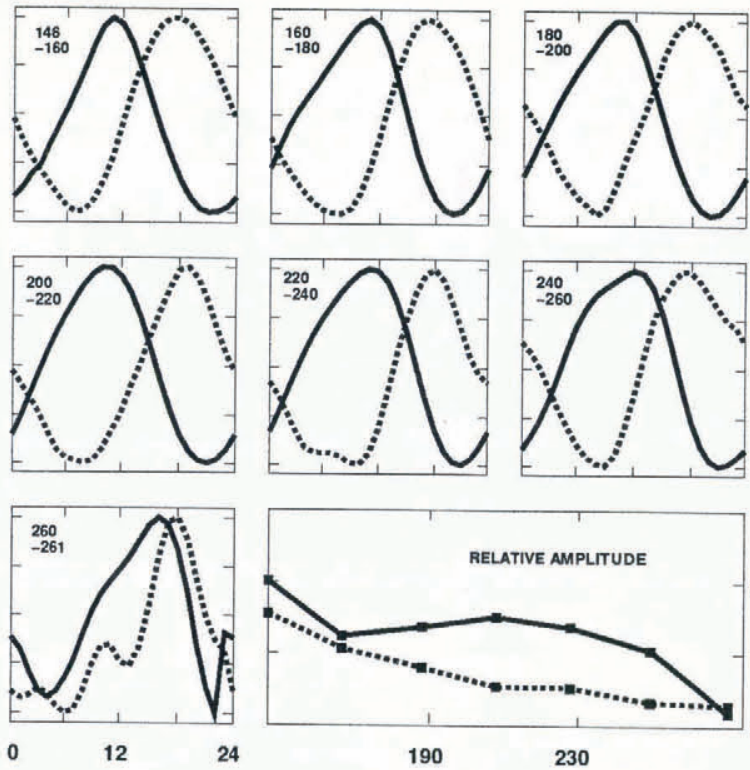

HOURS OF DAY
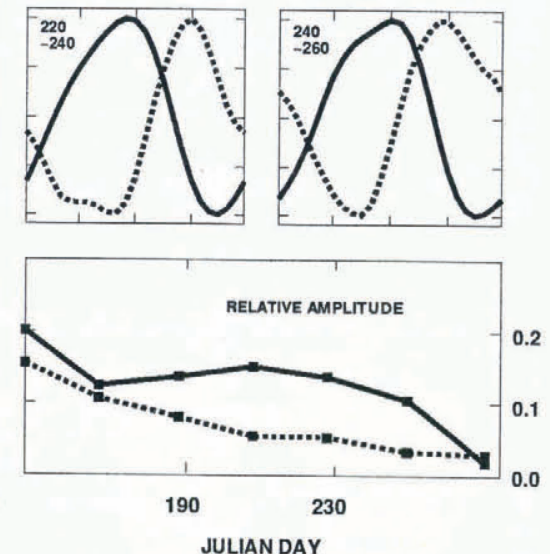

(b) FELS GLACIER, 1987
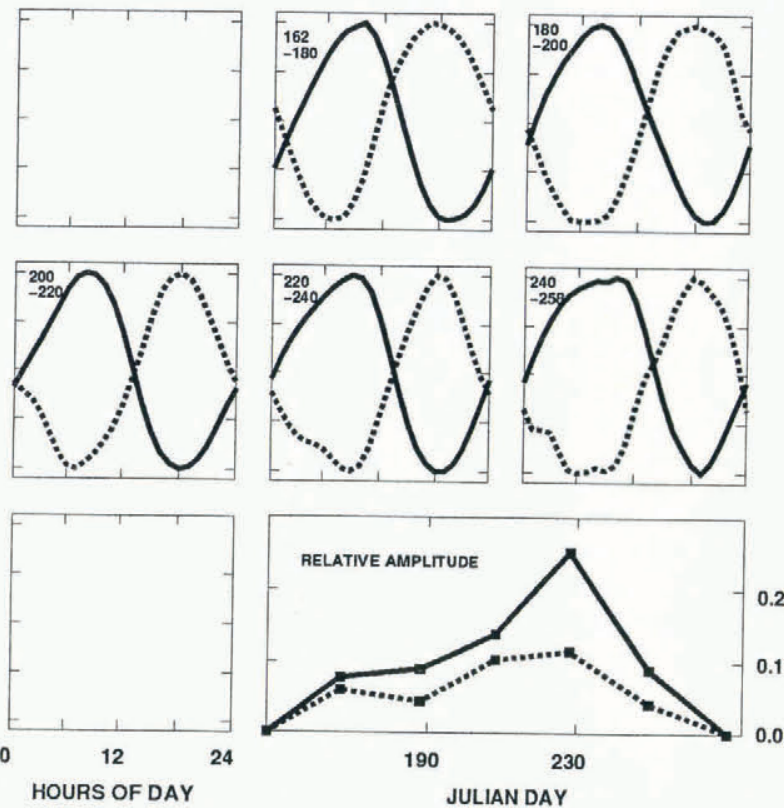

Fig. 5. Stage (dotted) and electrical conductivity (solid) variations stacked on $24 \mathrm{~h}$ intervals from midnight to midnight. Each box represents stacking over the interval of Julian days indicated in the box. The amplitudes are normalized for comparison of shapes and phases. The bollom right graph of each section shows the relative amplitude (half amplitude of variation divided by the mean) for each stacked interval.

variations of $Q$ and $C$ were approximately equal in magnitude and inversely related $(\hat{C} / \bar{C} \approx-\hat{Q} / \bar{Q})$, the relative amplitude of $Q C$ was small compared to the relative amplitudes of $Q$ and $C$. Table 3 summarizes relative amplitudes of water discharge $(\Delta Q / \bar{Q})$, solute concentration $(\Delta C / \bar{C})$ and solute discharge $(\Delta(Q C) / \overline{Q C})$ typical for the diurnal cycle on each glacier.

Figure 6 shows the relative timing of maxima and
Table 3. Properties of diurnal cycle

\begin{tabular}{|c|c|c|}
\hline & Black Rapids Glacier & Fels Glacier \\
\hline \multicolumn{3}{|l|}{ Water discharge } \\
\hline $\begin{array}{l}\Delta Q / Q \\
\text { Time of maximum }(\mathbf{h})\end{array}$ & $0.1-0.2$ & $0.1-0.2$ \\
\hline Time of minimum (h) & $\begin{array}{l}1800 \\
0800\end{array}$ & $\begin{array}{l}1800 \\
0800\end{array}$ \\
\hline \multicolumn{3}{|l|}{ Solutes } \\
\hline$\Delta C / \bar{C}$ & $0.1-0.2$ & $0.1-0.2$ \\
\hline Time of max $(h)$ & 1100 & 0900 \\
\hline Time of min (h) & 2100 & 1900 \\
\hline \multicolumn{3}{|l|}{ Solute flux } \\
\hline$\Delta(Q C) / \overline{Q C}$ & $<0.1$ & $<0.1$ \\
\hline \multicolumn{3}{|l|}{$\begin{array}{l}\text { Fast-system response } \\
\text { time and damping }\end{array}$} \\
\hline$\tau_{\mathrm{c}}(h)$ & $2.2-6.6$ & $2.2-6.6$ \\
\hline$\gamma_{e}$ & $0.5-0.9$ & $0.5-0.9$ \\
\hline \multicolumn{3}{|l|}{ Fast/slow partitioning } \\
\hline $\bar{Q}_{\mathrm{s}} / \bar{Q}$ & $0.6-0.9$ & $\begin{array}{ll}0.6 & 0.9\end{array}$ \\
\hline $\bar{Q}_{\mathrm{f}} / \bar{Q}$ & 0.40 .1 & $0.4-0.1$ \\
\hline \multicolumn{3}{|l|}{ Fast-system length } \\
\hline Time shift (h) & 3 & 1 \\
\hline Water speed $\left(\mathrm{km} \mathrm{h}^{-1}\right)$ & 6 & 5 \\
\hline Length $(\mathrm{km})$ & 18 & 5 \\
\hline Length/glacier length & 0.4 & 0.3 \\
\hline
\end{tabular}

minima for stage and EC found for each $20 \mathrm{~d}$ block for Black Rapids 1989 and Fels 1987 Glaciers. Typical times for the melt season are tabulated in Table 3. The stage varied with a maximum in the early evening (about $1800 \mathrm{~h}$ ) and minimum in the morning (about $0800 \mathrm{~h}$ ). Although we do not know precisely when maximum ablation rate occurs, a reasonable supposition is between $1400 \mathrm{~h}$ near solar noon (Alaska daylight time) and 1500 $1600 \mathrm{~h}$ when the air temperature reached its peak. Therefore, there is a time lag $\delta=2-4$ h of discharge behind input. There is also a lag of the early evening minimum and morning maximum in EC compared to the corresponding maximum and minimum in stage. The interval from the stage maximum to EC minimum defines a time shift listed in Table 3 under "fast-system length". The time shift is especially noticeable on Black Rapids Glacier $(\sim 3 \mathrm{~h})$. For either stage or EC, the time from the morning to evening extrema (maximum or minimum) was less than $12 \mathrm{~h}$ and the corresponding interval from evening to morning was longer. The rates of change were therefore most rapid during the daytime. The timing of the maxima and minima showed variations of a few hours through the melt season but no obvious progressive trends occurred during the observation periods.

The measurements of strain and seismicity showed that diurnal variations in the ice motion occurred on both glaciers (e.g. see Fig. 7.) The diurnal variations were not uniform in space and time. Diurnal variations were absent during winter but episodes of diurnal variations were observed as early as April. On either glacier at any one location, diurnal variations were not persistent (as is the case in the stream flow). Diurnal variations tended to be especially strong during prolonged motion events. Some locations were particularly susceptible to diurnal variations while others were less so. Phase of the diurnal variation of straining does 


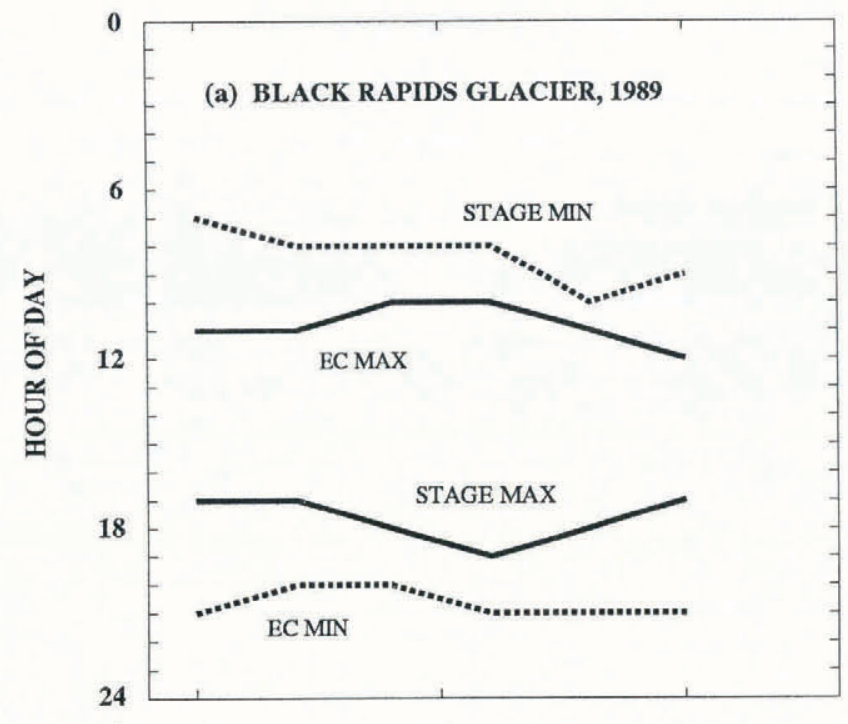

(b) FELS GLACIER, 1987

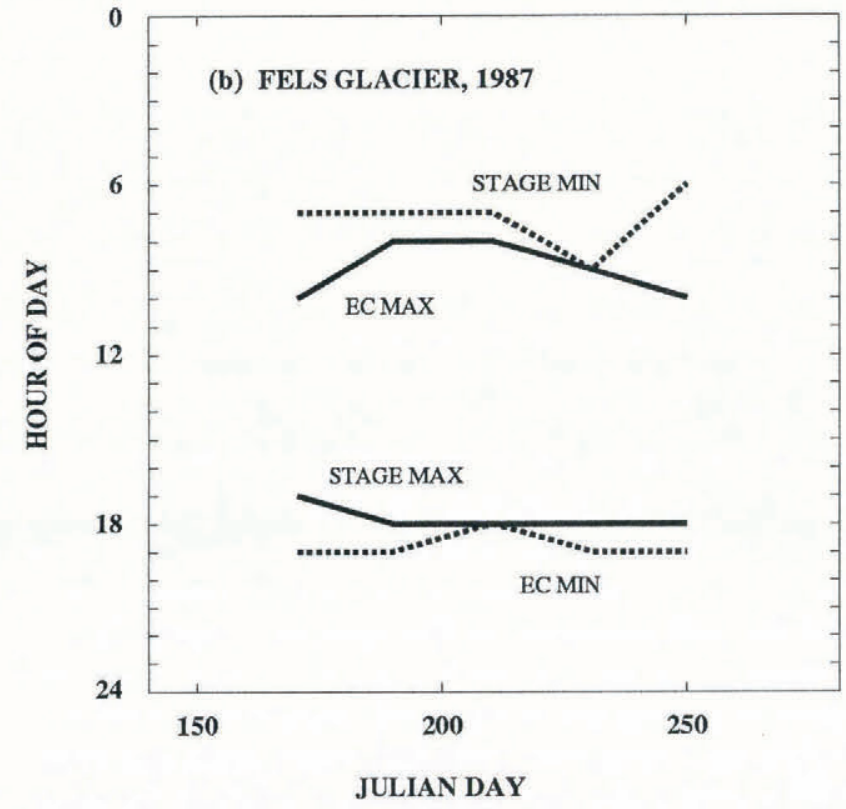

Fig. 6. Timing of diurnal maxima and minima of stage, EC and calibrated lurbidity over the summer season based on stacking in 20 d blocks (e.g. Fig. 4).

not appear to shift through the melt season but phases at different positions were not consistent.

\section{Events}

Abrupt changes in velocity, strain rate and/or acoustic emissions from the glaciers indicated event-like changes in motion. These motion events were infrequent or absent during the winter season but became common during the seasonal increase and decrease in velocity. Associated events usually occurred in the stream that were characterized by spike-like increases in TR lasting from hours to a few days. We refer to these as turbidity events. The turbidity events were often accompanied by related changes in EC or stage. A full catalogue of turbidity events that were identified on Fels and Black Rapids Glaciers during the observation periods has been given by Raymond and Benedict (1989). The times of identified events are indicated on Figure 3.

\section{BLACK RAPIDS GLACIER, 1987}
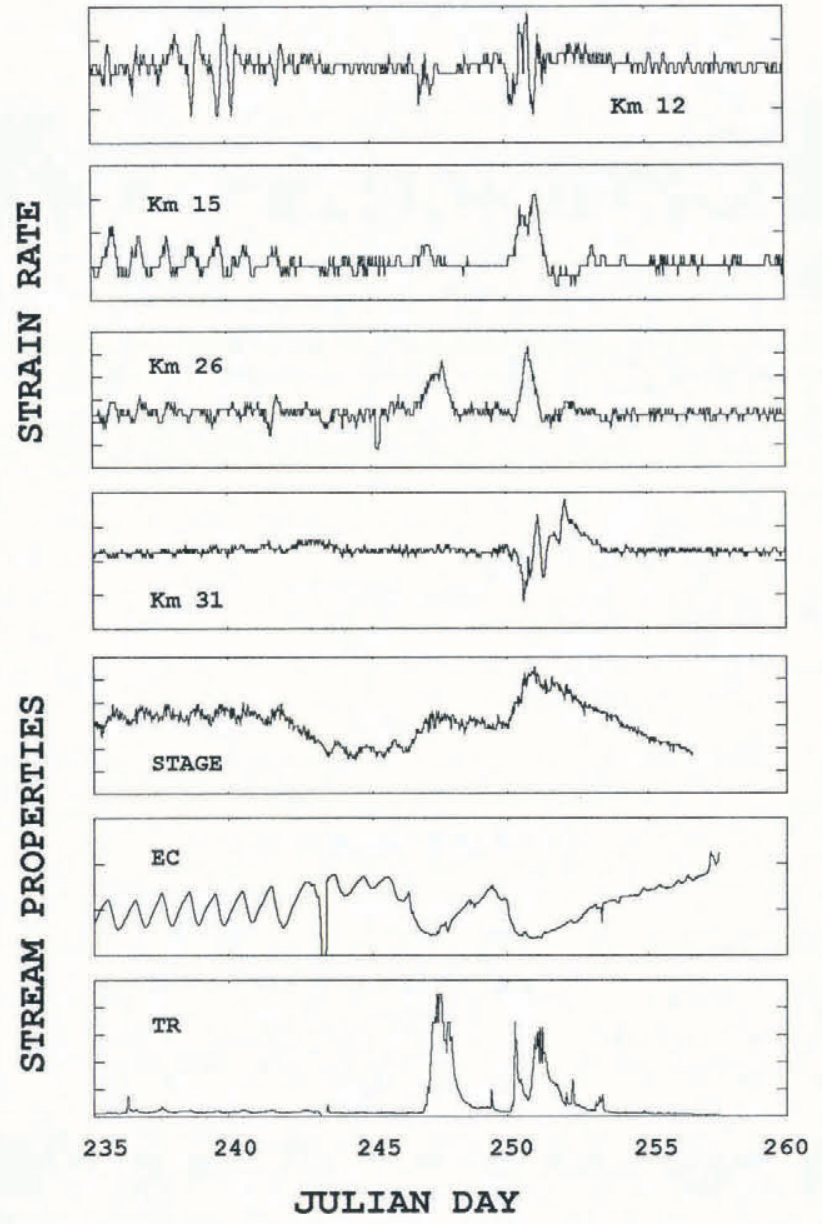

Fig. 7. Hydrological outputs in Black Rapids Glacier stream and strain-rate variations at locations measured from the head of Black Rapids Glacier during the fall of 1987. The interval Julian day 235-260 corresponds to 23 August -17 September. Two type I events (starting on days 247 and 250) occurred during this interval.

Two types of turbidity events can be distinguished. During type I events, there are obvious changes in EC corresponding to reduced solute concentration. The EC signal leads the TR signal by up to a few days. Figure 7 shows records for two type I events on Black Rapids Glacier in 1987 starting on days 247 and 250. Other examples of type I events can be seen in Figure 2 (e.g. Black Rapids Glacier 1989: days 180-185, days 251257). Type II events are not accompanied by identifiable changes in EC. Figure 8 shows an example of a type II event (days 197-198). Figure 2 shows other examples (e.g. Black Rapids Glacier, 1989: days 165-167, days 213215 , days 228-230). The classification in terms of type I and II events does not imply two definitely distinct kinds of event. For example, there are events where the occurrence of a related change in EC is small, indicating events transitional between types I and II (Fig. 3).

The occurrence of events varies during the seasons. Motion events did not occur during winter. Localized bursts of seismic activity and/or anomalous straining could occur, starting in April. The first major glacier- 


\section{BLACK RAPIDS GLACIER, 1987}

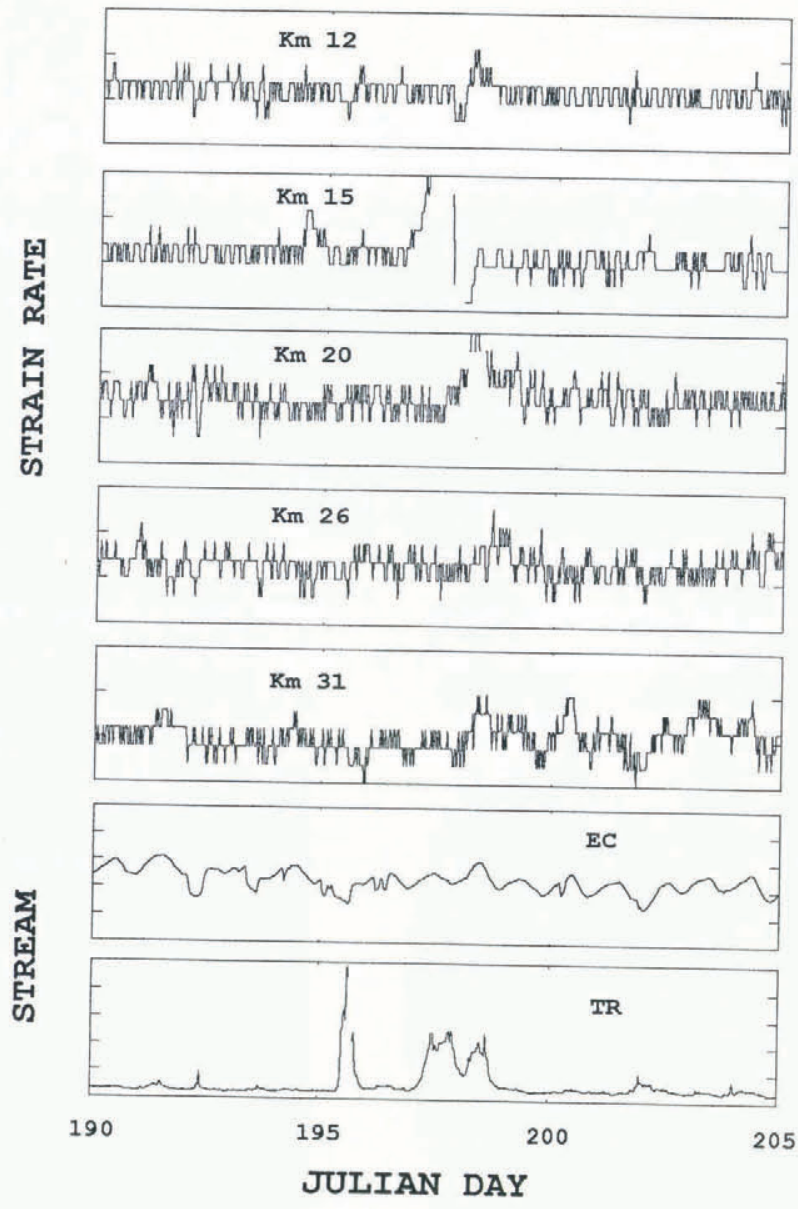

Fig. 8. Hydrological outputs in Black Rapids Glacier stream and strain-rate variations at locations measured from the head Black Rapids Glacier during the mell season of 1987. The interval Julian day 190-205 corresponds to 924 July. A type I event (day 195) and a type II event (days 197-198) occurred during this interval.

wide events of the melt season ("spring" events) occurred through May and June as $Q$ rose, EC dropped and TR increased in the streams. These events produced peaks in stage, TR and, often but not always, EC in the streams. Thus, the spring events were either type I or II as described above. The most dramatic events occurred late in the melt season ("fall" events). All three hydrological parameters showed distinct signals indicating type I behavior (e.g. Fig. 7). During spring or fall events, when there were changes in all three signals, the time progression of effects was usually ordered as follows: EC, TR, stage. The time interval between TR and stage "signals" was smaller than between EC and TR, and in some cases was not discernible from zero. The spring and fall events showed glacier-wide, nearly simultaneous changes in straining and seismicity (Fig. 7). The times of type I events were often correlated between Fels and Black Rapids Glaciers (Fig. 3), indicating influence of weather. The correlation is especially strong in fall events when storms affect both glaciers. Events were less common and more localized during the height of the melt season.

The type II event on Black Rapids Glacier shown in
Figure 8 coincides with the drainage of a marginal lake. The lake was located close to the strain site at $\mathrm{Km} 15$ near

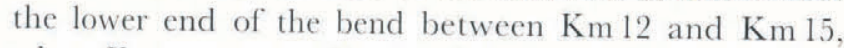
where $\mathrm{Km}$ represents distance from the head of the glacier in kilometers. The lake surface was photographed by a time-lapse camera. The lake rose over the previous month, started to drop gradually between days 192 and 196 (11-15 July) and at some time between days 196 and 204 (15-23 July) experienced a much more rapid rate of drop to near-empty. Absence of photographs between days 196 and 204 prevents determination of the exact timing and maximum rate of discharge from the lake. Lake volume was approximately $10^{6} \mathrm{~m}^{3}$, which corresponds to about $3 \mathrm{~h}$ of terminus discharge at the mean rate. There was no discernible water or solute discharge anomaly related to the lake drainage during the turbidity and straining activity.

The lake provided a localized input to the hydraulic system. The strain effects spread up- and down-glacier from the strain site at $\mathrm{Km} 15$ at speeds from 0.1 to $0.3 \mathrm{~km} \mathrm{~h}^{-1}$ (Fig. 8). They were attenuated over a distance scale of about $10^{1} \mathrm{~km}$ as shown by the small strain anomaly at $\mathrm{Km} 26$. The TR signal first appeared in the terminus stream on day 197.0 very soon after the onset of anomalous straining on day 196.6 at Km 15 (Fig. 8). If turbidity was first generated with the anomalous straining at $\mathrm{Km} \mathrm{15}$, then the average transfer velocity through the glacier hydraulic system to the stream would have been about $3 \mathrm{~km} \mathrm{~h}^{-1}\left(0.8 \mathrm{~m} \mathrm{~s}^{-1}\right)$.

In 1989, the lake drained on day 228 (16 August). In this instance, the lake discharged in part into supra- and near-surface, englacial passages linking "pot-holes" before descending to depth Sturm and Cosgrove, 1990). This drainage also produced a distinct type II event in the stream (Fig. 2a) but there are insufficient data to determine characteristics of strain propagation on the glacier. This and other lakes in the vicinity are known to have filled and drained on several occasions (probably annually). Such lake drainages may be the source of many of the type II events on Black Rapids Glacier.

\section{STRUCTURE OF THE DRAINAGE SYSTEMS}

\section{A. Background}

Passages carrying water through a glacier have been described according to their morphology as "channelized" in an arborescent tunnel system (Röthlisberger, 1972 or "distributed" in a linked network (e.g. Kamb, 1987), according to residence time as "quick" or "delayed" (e.g. Tranter and others, 1993), and according to their positions as "supraglacial", "englacial" or "subglacial" (e.g. Hooke, 1989). These in combination affect the motion of a glacier over its bed, the evacuation of subglacially derived rock debris and the introduction of solutes into the water from the atmosphere and rock. The discharge response of the passages to changes in water input is also of interest. The diurnal variations on glaciers indicate that compared to $\mathrm{ld}$ there are both fastresponding and slow (base-flow) components of the system (Röthlisberger and Lang, 1987). In this section, we examine how the diurnal variations and the coupled 
motion-turbidity events of Black Rapids and Fels Glaciers relate to the fast and slow components and to what extent fast/slow are related to channelized/distributed, quick/ delayed and supraglacial/englacial/subglacial partitions of the drainage system. Generally, it is assumed that channelized paths are larger, higher-speed passages compared to distributed ones, and therefore there is a correspondence between channelized and quick, and between distributed and delayed (e.g. discussion in Tranter and others (1993)), so these partitions may possibly be used interchangeably. However, the other partitions are likely to be overlapping. The discussion below leads us to distinguish three components that reflect combinations of the above: fast-quick, slow-quick and slow-delayed that arise because there is not necessarily a one-on-one correspondence between fast/slow and quick delayed. All three may have supraglacial, englacial and subglacial parts.

\section{B. Fast, slow and the diurnal cycle}

The diurnal cycle of water discharge contains information about the relative proportions of water going into fastand slow-responding components. The typical diurnal cycle (Fig. 5) is considered. Table 3 summarizes the observations of interest here: the amplitude of the diurnal fluctuation in water discharge $(\Delta Q / \bar{Q}=0.1-0.2)$ and its time lag behind input $(\delta=2-4 \mathrm{~h})$.

For the diurnal time-scale, we consider time-dependent deviations indicated by hatted variables from their corresponding time-independent mean values indicated by barred variables. We start by considering the theoretical behavior of a hypothetical flow path (reservoir) consisting of a conduit extending from the surface of the glacier to its terminus. Let $\iota$ and $q$ represent the water-volume input rate from the surface and the discharge rate from the exit, respectively. We make the following assumptions about the diurnal variations:

(i) The mean conditions correspond to a balance of input and output, so that

$$
\bar{q}=\bar{\iota} .
$$

(ii) Changes in the discharge $q$ occur as a result of changes in storage volume $v$ in the passage, so that in linearized form for small $\hat{q}$

$$
\hat{q}=\hat{v}(t) / \tau
$$

where

$$
\tau \equiv(\partial q / \partial v)^{-1}
$$

is a time-scale ("response time") evaluated for the mean conditions. Small changes in discharge and storage are then related like a linear reservoir (e.g. Oerter and others, 1981; Collins, 1982). This assumption implies that effects of any localization of storage are rapidly diffused so that the instantaneous discharge is related to the total storage.

(iii) The diurnal input varies sinusoidally as

$$
\hat{\imath}(t)=\Delta \iota \mathrm{e}^{\mathrm{i} \omega t}
$$

where $\omega=2 \pi /(1 \mathrm{~d})$. High-frequency components from non-sinusoidal input will not be resolved by this analysis.
While high frequencies are probably present in the input even in the averaged cycle, they are attenuated in the average output cycle (Fig. 5).

(iv) The amplitude of input fluctuation $\Delta \iota$ is equal to the mean input $\bar{\iota}$, which in combination with Equations (2) and (4) gives

$$
\Delta \iota=\bar{\iota}=\bar{q} .
$$

This relation is expected, since it is normal on these glaciers for melting to stop almost completely at night.

Volume conservation implies that

$$
\hat{q}(t)-\hat{\imath}(t)=\frac{\hat{\mathrm{d} v}}{\mathrm{~d} t}
$$

which expresses the balance amongst input, output and storage. Equations (3) and (6) give

$$
\frac{\mathrm{d} \hat{v}(t)}{\mathrm{d} t}+\frac{1}{\tau} \hat{v}(t)=\hat{\imath}(t) .
$$

For the input given by Equation (4), the solution of Equations (6) and (7) for $\hat{q}(t)$ is

$$
\hat{q}(t)=\Delta q \mathrm{e}^{\mathrm{i} \omega t}
$$

where

$$
\begin{gathered}
\tan (\omega \delta)=\omega \tau \\
\gamma=\frac{1}{\left(1+\omega^{2} \tau^{2}\right)^{0.5}}=\frac{1}{\left(1+\tan ^{2} \omega \delta\right)^{0.5}}=\cos (\omega \delta)
\end{gathered}
$$

and

$$
\Delta q=\gamma \mathrm{e}^{-\mathrm{i} \omega \delta} .
$$

Equations (8d) and (5) imply that

$$
|\Delta q|=\gamma \bar{q} .
$$

This model predicts a time lag $\delta$ of output behind input in the range 0 to one-quarter period $(6 \mathrm{~h})$ related to the response time $\tau$ (Equation (8b)). There is an associated damping factor $\gamma$ of the amplitude of output variation compared to the input (Equation (8c)). If $\omega \tau \gg 1$, then $\delta \rightarrow 6 \mathrm{~h}$ (one-quarter period) and $\gamma \rightarrow 0$ (strong damping). If, on the other hand, $\omega \tau \leq=1$, then $\delta \rightarrow 0 \mathrm{~h}$ and $\gamma \rightarrow 1$ (no damping). By Equations (8b) and $(8 \mathrm{c})$, the observed time lag $\delta(2-4 \mathrm{~h})$ corresponds to response time $\tau$ of $2.2-6.6 \mathrm{~h}$ and to a damping factor $\gamma$ of $0.9-0.5$.

The observations cannot be explained by one such flow path, since the observed time lag $(2-4 \mathrm{~h})$ and damping factor $(0.1-0.2)$ are inconsistent with Equations (8) (Fig. 9). One expects, in any case, that there are multiple flow paths, so this result is not surprising.

A superposition of paths can be described by a distribution of response times $\tau$ or an equivalent distribution $m(\delta)$ of time lags $\delta$ for the diurnal period as related through Equation $(8 \mathrm{~b})$. The range of time-scales is $[0, \infty]$ for $\tau$ and $[0, \pi / 2]$ for $\omega \delta$. The following analysis is developed using the distribution function $m(\omega \delta)$. Ex- 


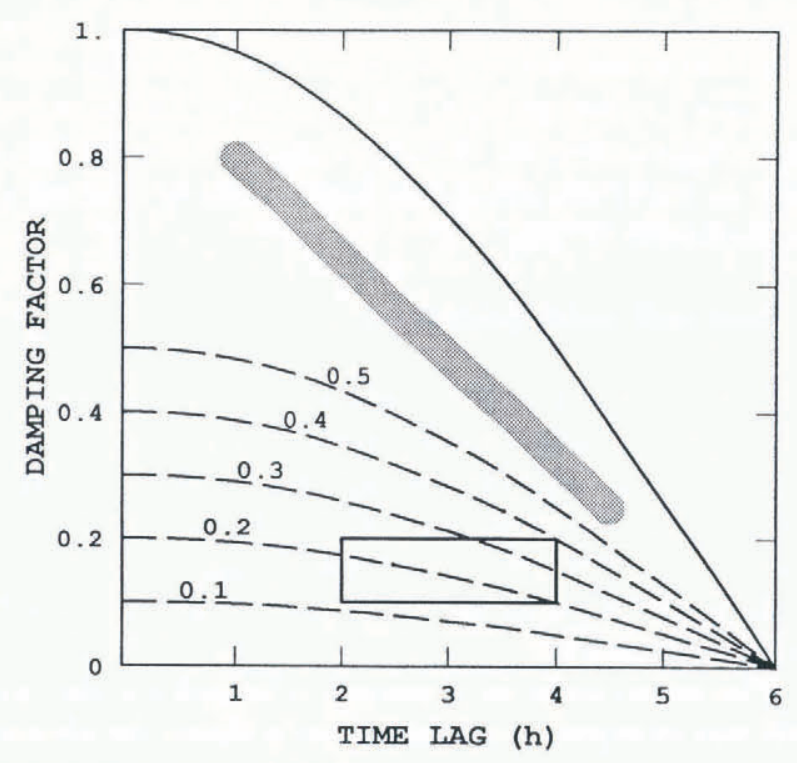

Fig. 9. Relations between effective damping factor $\gamma_{\mathrm{e}}$ and time lag $\delta_{\mathrm{e}}$. The box shows the range of observations. Solid curve represents predictions for a single flow path (Equation $(8 c))$. Dashed curves show predictions for two combinations of discrele components with time lags for a fast part $\delta_{\mathrm{f}}=\delta_{\mathrm{e}}$ and a slow part $\delta_{\mathrm{s}}=6 \mathrm{~h}$. Numbers on the curves show associated values of the ratio of the fast input to the total input. The stippled field shows the approximate boundary between combinations of $\gamma_{\mathrm{e}}$ and $\delta_{\mathrm{e}}$ with smooth distributions of $m(\delta)$ (Equation (10a)) that are double-peaked (below and to left) and that are singlepeaked (up and to the right toward the solid curve). Combinations of $\gamma_{\mathrm{e}}$ and $\delta_{\mathrm{e}}$ above and to the right of the solid curve cannol be predicted with smooth positive $m(\delta)$.

plicitly, let the amplitude of input fluctuation entering paths with time lag in the interval $\omega \delta_{1}$ to $\omega \delta_{2}$ be

$$
\Delta I\left[\omega \delta_{1}, \omega \delta_{2}\right]=\Delta I \int_{\omega \delta_{1}}^{\omega \delta_{2}} m(\omega \delta) \mathrm{d}(\omega \delta)
$$

where $\Delta I=\Delta I[0, \pi / 2]$ is the total amplitude of input fluctuation summed over all paths. It follows that the mean value of $\langle m\rangle$ is $2 / \pi$ on the interval $[0, \pi / 2]$. The distribution function $m$ represents the fraction of total input that goes into a given unit interval of $\omega \delta$. From Equation (5),

$$
\Delta I=\bar{I}=\bar{Q}
$$

where $\bar{I}$ and $\bar{Q}$ are the mean total input and output for the ensemble. Assuming that the passages are parallel and independent, the amplitude of discharge fluctuation corresponding to Equation (10a) is given by Equation (8d) to be

$$
\Delta Q\left[\omega \delta_{1}, \omega \delta_{2}\right]=\Delta I \int_{\omega \delta_{1}}^{\omega \delta_{2}} m(\omega \delta) \gamma(\omega \delta) \mathrm{e}^{-\mathrm{i} \omega \delta} \mathrm{d}(\omega \delta) .
$$

The amplitude of the total discharge fluctuation is $\Delta Q=\Delta Q[0, \pi / 2]$. From Equations (11), (10b) and (8c)

$$
\Delta Q=\gamma_{\mathrm{e}} \mathrm{e}^{-\mathrm{i} \omega \delta_{e}} \bar{Q}
$$

where

$$
\gamma_{\mathrm{e}} \mathrm{e}^{-\mathrm{i} \omega \delta_{\delta^{\prime}}}=\int_{0}^{\pi / 2} m(\omega \delta) \mathrm{e}^{-\mathrm{i} \omega \delta} \cos (\omega \delta) \mathrm{d}(\omega \delta)
$$

and $\gamma_{\mathrm{e}}$ and $\delta_{\mathrm{e}}$ represent effective damping and time lag for the combined discharge from the ensemble of passages. The distribution $m(\omega \delta)$ should give the observed characteristics $\delta_{\mathrm{e}}=2-4 \mathrm{~h}$ and $\gamma_{\mathrm{e}}=0.1-0.2$. We now consider several potential representations for $m(\omega \delta)$ with the purpose of matching the observations.

The smoothest multi-path model is a uniform distribution of time lag equal to the mean: $m(\omega \delta)=2 / \pi$. Integration of Equation (12b) with this distribution predicts $\delta_{\mathrm{e}}=2.17 \mathrm{~h}$ and $\gamma_{\mathrm{e}}=0.59$. While the predicted $\delta_{\mathrm{e}}$ is consistent with observation $(2-4 \mathrm{~h})$, predicted $\gamma_{\mathrm{e}}$ is larger than observed $(0.1-0.2)$. Therefore, this uniform distribution is not consistent with the observations.

One may consider inverting Equation (12b) for $m(\omega \delta)$ that best fits the data $\left(\gamma_{\mathrm{e}}\right.$ and $\left.\delta_{\mathrm{e}}\right)$. A unique inversion is not possible, even with precise data. (If $m(\omega \delta)$ fits the data and required mean value, any function that differs from $m$ by a zero-mean function that is orthogonal to $\mathrm{e}^{-\mathrm{i} \omega \delta} \cos (\omega \delta)$ will also fit equally as well.) This indeterminacy is fundamental to the data treatment, since we are examining the response to only one frequency of input $(\omega=2 \pi / d)$. To constrain the distribution of response times $\tau$ well would require data at (many) other frequencies. However, within the limitations of our data, the indeterminacy can be reduced with side conditions. For example, an inversion constrained to fit the data and mean value that also minimizes the integrated squared deviation of $m$ from its mean gives the pattern for $m(\omega \delta)$ shown in Figure 10. This is, in a sense, the smoothest representation that can fit the data. It shows high values at short and long time-scales with a minimum at intermediate scale $\delta_{\mathrm{t}} \approx 2-2.5 \mathrm{~h}$, which motivates the partitioning of the passages into two separate groups defining "fast" and "slow" systems,

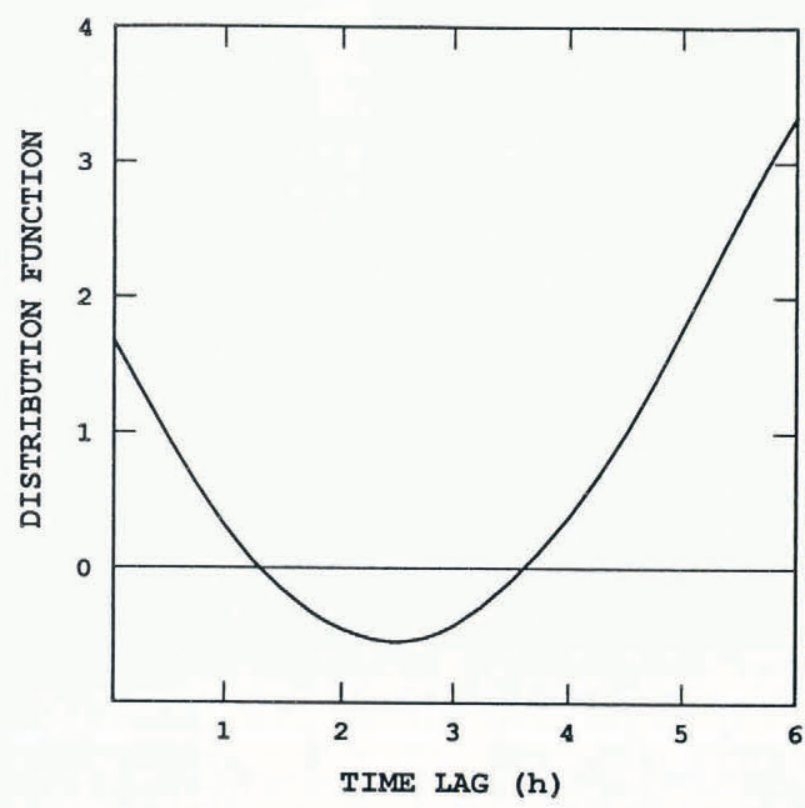

Fig. 10. Best-fit smooth distribution $m(\delta)$ for a time lag $\delta_{\mathrm{e}}=2 \mathrm{~h}$ and damping factor $\gamma_{\mathrm{e}}=0.2$. 
such that $\Delta I_{\mathrm{f}}=\Delta I\left[0, \omega \delta_{\mathrm{t}}\right], \Delta I_{\mathrm{s}}=\Delta I\left[\omega \delta_{\mathrm{t}}, \pi / 2\right], \Delta Q_{\mathrm{f}}=$ $\Delta Q\left[0, \omega \delta_{\mathrm{t}}\right]$ and $\Delta Q_{\mathrm{s}}=\Delta Q\left[\omega \delta_{\mathrm{t}}, \pi / 2\right]$. With these definitions

$$
\begin{array}{cl}
\Delta I=\Delta I_{\mathrm{f}}+\Delta I_{\mathrm{s}} & \Delta Q=\Delta Q_{\mathrm{f}}+\Delta Q_{\mathrm{s}} \\
\gamma_{\mathrm{f}} \mathrm{e}^{-\mathrm{i} \omega \delta_{\mathrm{f}}}=\Delta Q_{\mathrm{f}} / \Delta I_{\mathrm{f}} & \gamma_{\mathrm{s}} \mathrm{e}^{-\mathrm{i} \omega \delta_{\mathrm{s}}}=\Delta Q_{\mathrm{s}} / \Delta I_{\mathrm{s}} .
\end{array}
$$

These models of $m(\omega \delta)$ give partitioning into the fast and slow systems of about $\Delta I_{\mathrm{f}} / \Delta I \approx 0.05-0.1$ and $\Delta I_{\mathrm{s}} / \Delta I \approx 0.95-0.9$ with the fast system characterized by $\gamma_{\mathrm{f}} \approx 1$ and $\delta_{\mathrm{f}} \leq 2 \mathrm{~h}$ and the slow-system behavior $\gamma_{\mathrm{s}} \approx 0.1$ and $\delta_{\mathrm{s}} \geq 5 \mathrm{~h}$. The separation into two groups for the diurnal cycle appears to be forced by the combination of a relatively small time lag and strong damping. Singlepeaked $m(\omega \delta)$ is predicted for combinations of $\gamma_{\mathrm{e}}$ and $\delta_{\mathrm{e}}$ that are close to Equation (8c) (see Fig. 9).

Since the natural forcing is strongly focused at the diurnal time-scale, it does not seem necessary that the distribution of time-scales must be smoothly distributed. Furthermore, it is likely that the passages do not behave independently since they are linked and join into trunk passages (Röthlisberger and Lang, 1987). Especially, larger passages such as moulins feeding into pressurized tunnels are likely to behave coherently as a single component by sharing storage volume and influencing the hydraulic potential distribution in combination. These largest channelized passages are the ones likely to constitute the fast system. Smaller passages that form the slow system may act more heterogeneously. However, because of their slow response, they do not have a strong influence on the diurnal discharge variation, and the nature of their coupling, for example as a distributed network of passages, is unimportant for that question.

This reasoning suggests an alternative simpler model for fast/slow in the diurnal cycle that is composed of discrete components, for example, as has been utilized for run-off models with two (e.g. Lundquist, 1982) or more (e.g. Oerter and others, 1981) linear reservoirs. While the character of the diurnal cycle requires more than one component, two is the maximum that can be distinguished by the data description in terms of $\gamma_{\mathrm{e}}$ and $\delta_{\mathrm{e}}$. Suppose the fast system is described by a single time-scale $\delta_{\mathrm{f}}=\delta_{\mathrm{e}} \approx 2-4 \mathrm{~h}$ and a corresponding $\gamma_{\mathrm{f}} \approx 0.9-0.5$ (from Equations $(8 \mathrm{~b})$ and $(8 \mathrm{c}))$. Similarly, suppose that the slow system is described by $\delta_{\mathrm{s}}=6 \mathrm{~h}$ and a corresponding $\gamma_{\mathrm{s}}=0$. In terms of $m(\omega \delta)$, this model corresponds to two delta functions. The effective time lag $\delta_{\mathrm{e}}$ is controlled by $\delta_{\mathrm{f}}$, since $Q_{\mathrm{s}}$ with this assumption shows no diurnal time variation. The effective damping factor $\gamma_{e}$ for the combination can be fitted by adjusting the proportions of $\bar{I}_{\mathrm{f}}$ and $\bar{I}_{\mathrm{s}}$. This procedure gives $\bar{I}_{\mathrm{f}} / \bar{I}=0.4-0.1$ (Fig. 9) and hence $\bar{I}_{\mathrm{s}} / \bar{I}=0.6-0.9$. This discrete model also indicates a fast-system discharge that is less than that from the slow system.

Based on these considerations and the particular combination of damping (small $\gamma_{\mathrm{e}}$ ) and time lag (short $\delta_{\mathrm{e}}$ ) for the diurnal cycle, it is possible to make the following generalizations about the drainage systems of Black Rapids and Fels Glaciers: (i) there is a separation into fast and slow components; (ii) most of the input and discharge is through the slow components. Notice that, in general, (i) and (ii) are not necessarily requirements for a diurnal variation. For example, the even distribution of time-scales discussed above can give a distinct diurnal cycle, although with properties different from those observed on these glaciers. The separation that seems to exist suggests that the diurnal variation in water input plays an important role in the development of structure in the hydraulic system.

\section{Fast and quick passages}

The mean residence time associated with a passage is $r=\bar{v} / \bar{q}=\bar{v} / \bar{i}$, which is the replacement time for the storage volume $v$ by the through flow $q$. Here, the term "quick" will refer to short $r$ (<1d). (As used by Tranter and others (1993), the term "quick" appears to be less restrictive by referring only to short time in contact with subglacial materials.)

The requirement for a passage to be quick is that $q$ is sufficient to replace $v$ in a time that is short. An obvious extension of this requirement is that the storage thickness in the collection area of a quick conduit be smaller than the melt input over $1 \mathrm{~d}$, which means that quick passages cannot originate from surfaces that store liquid water with thickness more than several centimeters, such as snow, firn or highly weathered ice surfaces.

By Equation (3b), the requirement for a passage to be fast is that $q$ be sensitive to changes in $v$, so that $\tau=\partial v / \partial q$ is small. If $q$ and $v$ were linearly related, then $\tau=\partial v / \partial q$ and $r=\bar{v} / \bar{q}$ would be the same and there would be no distinction between fast and quick. However, the relationship between $q$ and $v$ may be non-linear (e.g. Gurnell, 1993), in which case it can be that $\tau \neq r$. The requirement for being quick is not necessarily sufficient for a passage to be fast.

As an example, consider a pressurized conduit with a cross-section that does not vary during a day. We allow that the passage is quick (short $r=\bar{v} / \bar{q}$ ), which in effect means the water velocity is high. The discharge $q$ is controlled by hydraulic gradient $J$, so for the passage to be fast $(q$ sensitive to changes in $v), J$ must be sensitive to $v$. Fluctuations in $v$ are accommodated by changes in water level $h$ in a feeder moulin. However, changes in $h$ do not significantly change the mean value of $J$, since the change in head is accompanied by an equal change in flow-path length, which together tend to have cancelling effects. To reduce the cancellation effect, it would be necessary for the drag and corresponding head loss to be especially low in the feeder moulin over the range of water-level fluctuation. Even with that condition, the sensitivity of $J$ to changes in $h$ falls off with distance from the terminus. Thus, it is possible that $\partial q / \partial v$ is small and $\tau=(\partial q / \partial v)^{-1}$ is large with the consequence that $\tau \gg r$. This illustrates that, theoretically, all quick passages are not necessarily fast.

If a passage is not pressurized, the discharge is sensitive to changes in water depth in the passage. The specific assumptions in this analysis (Equations (3)) do not account for thickness to change differentially along the passage, for example, associated with kinematic waves. However, if the length of open channel is short enough that the wave propagation over the length occurs over a time that is not longer than the response time $\tau$ characteristic of the fast system $(2.2-6.6 \mathrm{~h})$, then there would not be major effects from this source. A water speed of about $5 \mathrm{~km} \mathrm{~h}^{1}$ was measured by dye-tracing on Fels 
Glacier during the height of the melt season. A somewhat higher speed of about $6 \mathrm{~km} \mathrm{~h}^{-1}$ would be expected on Black Rapids Glacier based on scaling to account for difference in discharge and slope. The wave speed would be larger than the water speed (by a factor of about $\frac{5}{3}$ for a wide channel governed by Manning's equation). Propagation times would then be less than $1 \mathrm{~h}$ for openchannel lengths up to about $10 \mathrm{~km}$, which is longer than the expected length of near-terminus unpressurized subglacial tunnels or supraglacial streams. Therefore, one may expect a correspondence between fast and quick for open channels. (If one were to observe both low damping factor $\left(\gamma_{\mathrm{e}}\right)$ and long time lag $\left(\delta_{\mathrm{e}}\right)$ outside the possible range of the model (Fig. 9), one would possibly look to translational wave effects in open channels for an explanation.

This theoretical discussion suggests that fast is more restrictive than quick either in the sense of short total residence $(r)$ used here or short residence near the bed. The fast system is, therefore, also quick and must be composed of large, high-speed, short- $r$ open channels or pressurized tunnels fed by low-resistance moulins near the terminus. Fast behavior requires both no surface storage and proximity to the terminus, so the boundary between the collection areas for the fast and slow system should be down-glacier from the snow line, possibly by a considerable distance, after recession of the snow line on long glaciers.

\section{Slow and delayed passages}

Water flowing slowly through subglacial passages can interact chemically with the bed or bed-derived material to reach near-saturation related to active gaseous components in the water and composition of the bed. The combination of long residence and rock contact has been termed delayed flow Collins, 1979; Tranter and others, 1993; also termed subglacial by Collins (1979)). Following the original analysis by Collins (1979), we assume that mixing of delayed and quick discharges $Q_{\mathrm{d}}$ and $Q_{\mathrm{q}}$ ) conserves solutes, that $Q_{q}$ carries negligible solutes $\left(C_{\mathrm{q}}=0\right)$ and that $Q_{\mathrm{d}}$ carries solutes at a constant saturation concentration $C_{\mathrm{d}}$. Then, the total solute discharge is $Q C=Q_{\mathrm{d}} C_{\mathrm{d}}$. Since $Q C \approx$ constant over a day (section $3 \mathrm{~B}$ ), these assumptions imply also that $Q_{\mathrm{d}} \approx$ constant. Therefore, $Q_{\mathrm{d}}$ must be part of the slow system. An estimate of a lower limit to $C_{\mathrm{d}}$ is provided by the highest concentration reached at any time in the bulk flow. During the early melt seasons, $C$ exceeded twice the values typical of later in season (e.g. Fig. 2). This would imply that $Q_{\mathrm{d}} / Q \approx C / C_{\mathrm{d}} \leq 0.5$, which is less than $Q_{\mathrm{s}} / Q$ estimated above. Therefore, $Q_{\mathrm{d}}$ is only a fractional part of $Q_{\mathrm{s}}$. This result implies $Q_{\mathrm{s}}$ has quick passages, which is consistent with the earlier conclusion that all quick passages are not necessarily fast. Raiswell (1984) and Tranter and others (1993) showed that mixing of quick and delayed waters may not be conservative because of post-mixing reactions between dilute, quick water and suspended sediment. Accounting for the additional solutes would increase the predicted proportion of quick water and thereby strengthen the conclusion that the slow system contains quick passages. One can therefore distinguish two parts to the slow system: slow-delayed and slow-quick.
With this view of the slow system, its role in the diurnal discharge of solutes can be complex. Since the slow system does not experience significant diurnal waterdischarge variations (because changes in mean hydraulic gradient are small), variations in its solute output concentration cannot be controlled by dilution in the way discussed above. Nevertheless, the way quick and delayed parts are mixed could vary (because pressure changes could be significant), thus leading to changes in the interaction kinetics, solute acquisition and consequent solute discharge from the slow system (e.g. Collins, 1979). Since the solute discharges from Black Rapids and Fels Glaciers were approximately constant during the diurnal cycle, it appears that the dominant effect was dilution of a nearly constant slow-system solute flux by the variable relatively pure fast discharge, with interaction kinetics in the slow system and in the mixed fast/slow water being secondary features. Our data are not sufficient to investigate these features well, because we do not have information about chemical species, which can reveal characteristics of the mixing (e.g. Tranter and others, 1993). Focusing on the primary features here, the relative amplitude of the the solute concentration $0.1-0.2$; Table 3 ) gives a measure of the proportion of the fast to the total discharge, which would suggest a fast discharge in the lower part of the range deduced in section $4 \mathrm{~B}$.

The time shift between diurnal stage and EC variations (section $3 \mathrm{~B}$; Table 3 ) combined with a transport velocity determines a length scale that is possibly related to the locations where solutes were diluted by joining of the fast and slow systems. If mixing

occurred at a distance $D$ up-flow from the portal of a pressurized tunnel, then the time shift would be $D / u$, where $u$ is the physical water speed in the tunnel transporting the combined fast and slow water. Based on the water velocities described earlier (section 4C) and the observed time shifts (Table 3), the effective soluteinjection distance $D$ above the terminus is about 0.30 .4 of the full length of each glacier. The absolute distances are, however, quite different on each glacier $18 \mathrm{~km}$ on Black Rapids Glacier and $5 \mathrm{~km}$ on Fels Glacier). The time shift, therefore, supports the notion that the fast system is restricted to the lower parts of the ablation areas of these glaciers. It should also be borne in mind that the timeshift might be caused by a time-varying solute discharge from the slow system associated with some of the secondary features mentioned above.

\section{E. Thresholds in the slow system}

The turbidity events often show rapid changes on timescales less than a day but they can last several days. The strong changes in the discharge of suspended sediment and the related motion events indicate that the phenomena involve large areas of the bed. Distributed passages in the subglacial part of the slow-delayed system must play a dominant role.

The abrupt onset of turbidity events indicates a threshold. On average, the water must flow from the slow to the fast system to be discharged from the glacier and the head must normally be higher in the slow system than the fast one. When water input is abnormally high, the storage and head may be driven up to high values 
that are sufficient to inject water from the englacial parts of the slow system into subglacial parts along the bed. This, in turn, can increase the hydraulic transmissivity and mobilize erosion products produced and/or stored at the bed (Collins, 1989).

The type II events appear to be similar to "minisurges" of Variegated Glacier (Humphrey and others, 1986; Raymond and Malone, 1986; Kamb and Engelhardt, 1987). The type II event on Black Rapids Glacier in 1987 (section 3C; Fig. 8) is the best-documented example. A strain wave moved down-glacier at a speed similar to the Variegated Glacier mini-surges $(0.2$ $0.3 \mathrm{~km} \mathrm{~h}^{-1}$ ), which suggests a similar mechanism. Minisurges were hypothesized to occur by propagation of an hydraulic wave initiated locally by release of a reservoir. In this case, the reservoir was a marginal lake. It filled slowly and probably contained well-mixed surface melt and ground water, which could account for the lack of distinct EC changes that is common to type II events and "mini-surges".

From the observations (section 3C), the speed of turbidity transfer (about $3 \mathrm{~km} \mathrm{~h}^{-1}$ ) was much faster than the strain-wave propagation $\left(0.2-0.3 \mathrm{~km} \mathrm{~h}^{-1}\right)$. Indeed, the turbidity pulse reached the terminus at $\mathrm{Km} 41$ before the strain wave spread from Km 15 to $\mathrm{Km} 20$ (Fig. 8). This behavior shows the existence of quick-flow paths from near the site of the lake to the terminus, encompassing $70 \%$ of the glacier length. The lack of a discernible waterdischarge anomaly suggests that these quick passages are not necessarily fast. Together, these results support the notion that quick passages are much more extensive than fast ones.

The low propagation speed of the hydraulic effects may have been associated with storage by expansion of subglacial delayed (distributed) passages, for example, as proposed for "mini-surges" by Kamb and Engelhardt (1987) and Raymond and Malone (1986), and modeled by Fahnestock (1991). Although there may have been net flow of water into basal storage during the initial phases of the event, the high turbidity indicates there must have been substantial recycling of water between the bed where turbidity could be generated and the quick-flow paths that transported it at high speed. The combination of widespread surface straining and rapid appearance of turbidity in the stream indicates that, at least during the event, there were strong transverse connections that allowed hydraulic effects to spread laterally across the glacier width. This is necessary to affect a sufficient area of the bed to disturb the motion and to allow turbidity to reach quick longitudinal flow paths very rapidly.

Type I events appear to be related to weather-induced surface-water input that is non-local (section 3C). The premonitory EC signal associated with these type I events can be explained as a dilution effect from the fast system caused by higher-than-normal amounts of clean water entering into the drainage system from the surface relatively near the terminus. This dilution occurs nearly contemporaneously with the beginning of anomalous weather. This process is similar to the dilution that occurs during the afternoon of the diurnal cycle.

Although the stimulus for type I events may affect wide areas nearly simultaneously, the response of the slow system at the bed may be heterogeneous, presumably depending on the details of the near-surface storage, flow paths from the surface to the bed and morphology of the bed, which in combination will affect the rate of pressure change and the threshold pressure needed to inject water to new areas of the bed. This is indicated by the diverse response of strain meters during type I events and the lack of a consistent diurnal variation in strain at different meter locations. It is also consistent with measurements on other glaciers in boreholes, which may or may not "connect" to the basal hydraulic system depending on where the bed is reached (e.g. Hodge, 1979) and that show high spatial variability for short time-scale, low- to moderate-amplitude variations not associated with major events (Iken and Bindschadler, 1986). The very large events that affect all locations may be associated with especially dramatic increase in the transmissivity of some of the paths of the slow system along the bed, thus coupling different parts of the system more strongly than during normal conditions.

\section{F. Seasonal changes}

On a number of glaciers, the maximum discharge in the diurnal cycle occurs earlier in the day as the melt season progresses (Paterson, 1981, chapter 8). This change in time lag is related in part to retreat of the snow line (e.g. Fountain, 1992). Neither Black Rapids nor Fels Glaciers shows any obvious progressive trend in the timing of the diurnal discharge cycle through the observed parts of the melt seasons. If a trend exists, it must be largely completed in the very early part of the melt season before late May and the major increase in average discharge. This behavior may be explained by the confinement of the fast system to the near-terminus region and the very rapid recession of the snow line from the lower parts of these glaciers because of thin snow cover and rapid warming in the early melt season. However, that explanation is not complete. In the context of our analysis of the fast system, the lack of trend in the timing of the discharge maximum would require a parallel evolution of variables to hold the response time $\tau$ (Equation (3b)) approximately constant. Dye injections were made into a large moulin on Fels Glacier before (Julian day 160) and after (Julian day 199) the spring events and major increase in stage in 1987 (Fig. 2b). Comparison of results from the two injections showed that the mean water speed increased by a factor of 1.7 and the day-averaged water discharge increased by more than a factor of 2, which together indicate an increase in the flow cross-section. Whatever the evolution of the fast system, it does not strongly affect time response in the diurnal cycle.

The spring events apparently play a role in the transition from winter to summer conditions as found on other glaciers (Röthlisberger and Lang, 1987). The earliest spring events sometimes alter the slow system, as evidenced by distinct before-to-after changes in mean water and sediment discharges (e.g. Fig. 2b). The beforeto-after increase in water discharge indicates an increase in transmissivity of the slow system that slows or reverses the build-up of storage. This kind of active role of the events in the evolution of the drainage system is similar to the mini-surges of Variegated Glacier, where there was a before-to-after drop in basal water pressure measured in 
boreholes and often an increase in ice speed (Kamb and Engelhardt, 1987). The increase in transmissivity must come in part from enlargement of existing passages to the extent that some of them become quick passages (tunnels) transporting water at high speed. The before-to-after increase in sediment discharge indicates that new passages are initiated during the event and that some of these remain open to access new sediment sources on the bed. This suggests enlargement of the subglacial parts of both the slow-delayed and slow-quick drainages by the spring events as well as by more continuous evolution.

Some spring events, especially later ones, do not cause distinct before-to-after changes in hydrological or dynamical behavior. In these cases, the events seem to be passive indicators of conditions in the hydraulic system that have not completely adjusted to increasing water input. Presumably, the low occurrence of events during mid-summer is explained by the evolution of the passages to give increased transmissivity of the slow system. That allows the water input to be transferred at lower pressures, thus making the threshold for event occurrence less attainable.

With decreasing mean water input in the late melt season, the opposite evolution of transmissivity should occur, thus allowing high pressures to develop again during transiently high water input from fall storms. This behavior has been previously suggested to explain late melt-season events on Variegated Glacier (Harrison and others, 1986) and Unteraargletscher (Iken and others, 1983). Although the fall events may occur because the passages of the slow system have contracted, these events probably do not contribute to the closure and may in fact temporarily retard it. Events in September are sometimes followed by a progressive decline in water discharge and the amplitude of the diurnal cycle (Fig. 2a). This change is most likely explained by an abrupt change in meltwater input, for example, caused by snowfall in the later part of the fall storm associated with the event. If the input drop were abrupt, as is likely but not certain, the discharge recession indicates that the response time $\tau$ for most of the system (slow system) is several days.

\section{SUMMARY}

The hydrological behaviors of Black Rapids and Fels Glaciers are similar on the seasonal and diurnal timescales defined by the observations. On each glacier, the typical diurnal variation of water discharge has a relatively small half-amplitude of $0.1-0.2$ of the mean with a short time lag of output behind input of a few hours. To explain this combination of observations requires that the total discharge be a superposition of slow parts that do not respond to diurnal input and fast parts that do respond with large amplitude and short time lag. The slow parts carry $0.8-0.9$ of the total, which accounts for the low amplitude of diurnal variation. The remaining $0.1-0.2$ of the total is transferred through the fast parts, which accounts for the short time lag. The fast parts are restricted to the lowermost $0.3-0.4$ or less of the glacier length. Small differences in the diurnal timing of water and solute discharges between Black Rapids and Fels Glaciers can be explained by the differences in glacier length without recourse to any differences in basic structure of the drainage systems. We have emphasized a fast/slow partitioning of the drainage system, which describes the discharge response to input variations. This cannot be equated to quick/delayed partitionings, which describes residence time. The fast system is composed of quick passages but the slow system appears to have both quick and delayed passages. These three groups may all have supra-, en- and subglacial parts.

Although our methods for analyzing the hydrological system are different and emphasize different parameters, our conclusions about the morphology and connections of the drainage system fit the mold synthesized from many observations on Alpine glaciers, for example, as reviewed by Röthlisberger and Lang (1987, e.g. fig. 10.11). In this regard, and in the context of the seasonal and diurnal observations that we have reported, Black Rapids and Fels Glaciers appear to be hydrologically "normal". In particular, if there is a difference in bed structure that is responsible for surge behavior of Black Rapids Glacier, it did not affect the seasonal and diurnal hydrology during the observation years.

Both Black Rapids and Fels Glaciers experience coupled motion and hydrological events. Two types of hydrological events can be identified according to the occurrence of dilution of solute concentration (type I) or not (type II). One difference between the two glaciers is that type II events are prominent on Black Rapids Glacier but not on Fels Glacier. Our interpretation is that type I events that occur on both glaciers, sometimes nearly simultaneously, result from glacier-wide input of extra water associated with weather events. Type II events on Black Rapids Glacier appear to be associated with localized and gradual build-up of water in marginal lakes released suddenly by internal processes rather than immediate weather. The type II events are similar to the "mini-surges" found on Variegated Glacier during the quiescent phase between its surges.

Motion and hydrological events occur on a number of glaciers that are not known to surge (Iken and others, 1983; Iken and Bindschadler, 1986; Hooke and others, 1989), now including Fels Glacier. Therefore, events in general do not appear to be indicative of surge behavior. However, one may ask whether the type II events are associated with surge-type glaciers. Based on our understanding of how the type II events arise and their commonality and differences with type I events, we do not see any reason that they would be restricted to surgetype glaciers. Events with hydrological character similar to type II defined here have been observed on glaciers that are not known to surge (Collins, 1989) but the dynamic character of these events is not known. To resolve the significance of type II events, it is necessary to have more complete combined hydrological and dynamical descriptions of events on normal glaciers that distinguish between immediate weather events and local internally controlled triggering.

\section{ACKNOWLEDGEMENTS}

This research was supported by U.S. National Science Foundation grants DPP8520527 and DPP8519110. N. 
Humphrey, H. Fried, M. Schwitter and R. Wilson made major contributions to the field work. Comments from A. Iken, R. Le B. Hooke and an anonymous reviewer greatly helped to improve the manuscript.

\section{REFERENCES}

Bindschadler, R., W. D. Harrison, C. F. Raymond and R. S. Crosson. 1977. Geometry and dynamics of a surge-type glacier. J. Glaciol., 18 - 79 , 181-194.

Collins, D. N. 1979. Quantitative determination of the subglacial hydrology of two Alpine glaciers. f. Glaciol., 23 89), 347-362.

Collins, D. N. 1982. Water storage in an Alpine glacier. International Association of Hydrological Sciences Publication 138 (Symposium at Exeter 1982 - Hydrological Aspects of Alpine and High-Mountain Areas), 113 122.

Collins, D. N. 1989. Seasonal development of subglacial drainage and suspended sediment delivery to melt waters beneath an Alpine glacier. Ann. Glaciol., 13, 45-50.

Fahnestock, M.A. 1991. Hydrologic control of sliding velocity in two Alaskan glaciers: observation and theory. Ph.D. thesis, California Institute of 'Technology.

Fountain, A.G. 1992. Subglacial water flow inferred from stream measurements at South Cascade Glacier, Washington State, U.S.A. 7. Glaciol., 38 (128), $51-64$.

Greenberg, A. E., J.J. Connors and D. Jenkins, eds. 1981. Standard methods for the examination of water and waste water. Fifleenth edition. New York, American Public Health Association.

Gurnell, A.M. 1993. How many reservoirs? An analysis of flow recessions from a glacier basin. J. Glaciol., 39(132), 409414.

Hance, J.H. 1937. The recent advance of Black Rapids Glacier, Alaska. 7. Geol., 45, 775 .

Harrison, W. D. 1990. Final data report. Basal processes and glacier motion. University of Alaska. Available from World Data Center A-Glaciology.

Harrison, W. D., L. R. Mayo and D. C. Trabant. 1975. Temperature measurements of Black Rapids Glacier, Alaska, 1973. In Weller, G. and S. A. Bowling, eds. Climate of the Arctic. Proceedings of the 24th Alaska Science Conference. Fairbanks, AK, University of Alaska, 350 352.

Harrison, W. D., C. F. Raymond and P. MacKeith. 1986. Short period motion events on Variegated Glacier as observed by automatic photography and seismic methods. Ann Glaciol., 8, 8289.

Harrison, W. D., K. A. Echelmeyer, D. M. Cosgrove and C. F. Raymond. 1992. The determination of glacier speed by time-lapse photography under unfavorable conditions. f. Glaciol., 38 (129), 257-265.

Harrison, W. D., K. A. Echelmeyer and H. Engelhardt. 1993. Shortperiod observations of speed, strain and seismicity on Ice Stream B, Antarctica. J. Glaciol., 39 133), 463-470.

Hodge, S. M. 1974. Variations in the sliding of a temperate glacier. $\mathcal{F}$. Glaciol., 13 (69), 349-369.

Hodge, S.M. 1979. Direct measurement of basal water pressure: progress and problems. f. Glaciol., 23 (89), 309-319.

Hooke, R. LeB. 1989, Englacial and subglacial hydrology: a qualitative review. Arct. Alp. Res., 21 (3), 221-233.
Hooke, R. LeB., P. Calla, P. Holmlund, M. Nilsson and A. Stroeven. 1989. A 3 year record of seasonal variations in surface velocity, Storglaciären, Sweden. J. Glaciol., 35 (120), 235-247.

Humphrey N., C. Raymond and W. Harrison. 1986. Discharges of turbid water during mini-surges of Variegated Glacier, Alaska, U.S.A. J. Glaciol., 32(111), 195-207.

Iken, A. and R.A. Bindschadler. 1986. Combined measurements of subglacial water pressure and surface velocity of Findelengletscher, Switzerland: conclusions about drainage system and sliding mechanism. 7. Glaciol., 32(110), 101-119.

Iken, A., H. Röthlisberger, A. Flotron and W. Haeberli, 1983. The uplift of Unteraargletscher at the beginning of the melt season-a consequence of water storage at the bed? J. Glaciol., 29(101), $28-47$.

Kamb, B. 1987. Glacier surge mechanism based on linked cavity configuration of the basal water conduit system. \%. Geophys. Res., 92 B9), $9083-9100$.

Kamb, B. and H. Engelhardt. 1987. Waves of accelerated motion in a glacier approaching surge: the mini-surges of Variegated Glacier, Alaska, U.S.A. J. Glaciol., 33(113), 27-46.

Kamb, B. and 7 others. 1985. Glacier surge mechanism: $1982-1983$ surge of Variegated Glacier, Alaska. Science, 227 (4686), 469-479.

Lundquist, D. 1982. Modelling runoff from a glacierized basin. International Association of Hydrological Sciences Publication 138 (Symposium at Exeter 1982 Hydrological Aspects of Alpine and High-Mountain Areas), 131-136.

Oerter, H., D. Baker, H. Moser and O. Reinwarth. 1981. Glacialhydrological investigations at the Vernagtferner glacier as a basis for a discharge model. Nord. Hydrol., 12, 335-348.

Paterson, W. S. B. 1981. The physics of glaciers. Second edition. Oxford, etc., Pergamon Press.

Post, A. 1969. Distribution of surging glaciers in western North America. 7. Glaciol., 8 (53), 229-240.

Raiswell, R. 1984. Chemical models of solute acquisition in glacial melt waters. J. Glaciol., 30 (104), 49-57.

Raiswell, R. and A. G. Thomas. 1984. Solute acquisition in glacial melt waters. I. Fjallsjökull (south-east Iceland): bulk melt waters with closed-system characteristics. J. Glaciol., 30 (104), 4448.

Raymond, C.F. and R. Benedict. 1989. Final technical report. Basal processes and glacier motion. Available from World Data Center A Glaciology.

Raymond, C.F. and S. Malone. 1986. Propagating strain anomalies during mini-surges of Variegated Glacier, Alaska, U.S.A. J. Glaciol., 32 111), 178-191.

Röthlisberger, H. 1972. Water pressure in intra- and subglacial channels. J. Glaciol., $11(62)$, 177-203.

Röthlisberger, H. and H. Lang. 1987. Glacial hydrology. In Gurnell, A. M. and M.J. Clark, eds. Glacio-fluvial sediment transfer; an alpine perspective. Chichester, etc., John Wiley and Sons, 207-284.

Sturm, M. and D. M. Cosgrove. 1990. Correspondence. An unusual jökulhlaup involving potholes on Black Rapids Glacier, Alaska Range, Alaska, U.S.A. f. Glaciol., 36(122), 125-126.

Thomas, A. G. and R. Raiswell. 1984. Solute acquisition in glacial melt waters. II. Argentière (French Alps): bulk melt waters with opensystem characteristics. J. Glaciol., 30 (104), 4448.

Tranter, M., G. Brown, R. Raiswell, M. Sharp and A. Gurnell. 1993. A conceptual model of solute acquisition by Alpine glacial meltwaters. f. Glaciol., 39 (133), $573-581$. 